\title{
Individual Radiation Protection Monitoring in the Marshall Islands: Rongelap Island Resettlement Support (1998-2001)
}

Terry Hamilton, David Hickman, Cynthia Conrado, Thomas Brown, James Brunk, Alfredo Marchetti, Carolyn Cox, Roger Martinelli, Steven Kehl, Ericson Arelong ${ }^{1}$, Simon Langinbelik1, $R$. Thomas Bell2, and Gerald Petersen²

The following document has been prepared as a hardcopy supplement to the U.S. Department of Energy web site, http://tis. eh.doe.gov/health/rwdl. This report has been prepared in partial fulfillment of LLNL program level goals and actions supporting Rongelap Atoll resettlement as formally outlined under a Memorandum of Understanding (MOU) between the U.S. Department of Energy, the Republic of the Marshall Islands, and the Rongelap Atoll Local Government.

1 Rongelap Atoll Local Government, P.O. Box 238, Majuro MH 96960

2 Office of Health Studies, U.S. Department of Energy,EH-6/270CC, 19901 Germantown Rd., Germantown, MD 20874-1290 


\section{DISCLAIMER}

This document was prepared as an account of work sponsored by an agency of the United States Government. Neither the United States Government nor the University of California nor any of their employees, makes any warranty, express or implied, or assumes any legal liability or responsibility for the accuracy, completeness, or usefulness of any information, apparatus, product, or process disclosed, or represents that its use would not infringe privately owned rights. Reference herein to any specific commercial product, process, or service by trade name, trademark, manufacturer, or otherwise, does not necessarily constitute or imply its endorsement, recommendation, or favoring by the United States Government or the University of California. The views and opinions of authors expressed herein do not necessarily state or reflect those of the United States Government or the University of California, and shall not be used for advertising or product endorsement purposes.

This work was performed under the auspices of the U. S. Department of Energy by the University of California, Lawrence Livermore National Laboratory under Contract No. W-7405-Eng-48.

This report has been reproduced directly from the best available copy.

Available electronically at http://www.doc.gov/bridge

Available for a processing fee to U.S. Department of Energy

And its contractors in paper from

U.S. Department of Energy

Office of Scientific and Technical Information

P.O. Box 62

Oak Ridge, TN 37831-0062

Telephone: (865) 576-8401

Facsimile: (865) 576-5728

E-mail: reports@adonis.osti.gov

Available for the sale to the public from

U.S. Department of Commerce

National Technical Information Service

5285 Port Royal Road

Springfield, VA 22161

Telephone: (800) 553-6847

Facsimile: (703) 605-6900

E-mail: orders@ntis.fedworld.gov

Online ordering: http://www.ntis.gov/ordering.htm

OR

Lawrence Livermore National Laboratory

Technical Information Department's Digital Library

http:/ / www.llnl.gov/tid/Library.html 


\section{Table of Contents}

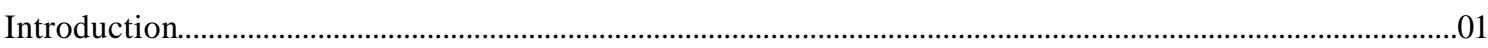

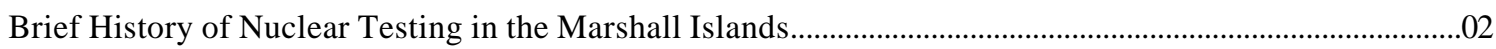

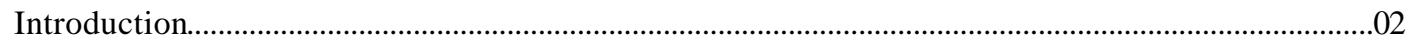

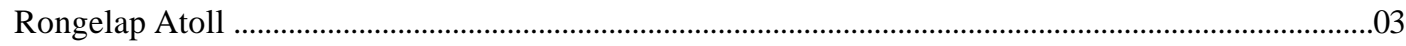

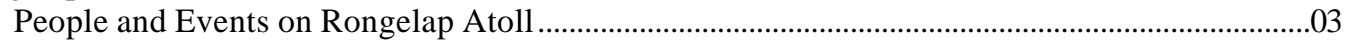

Resettlement of Rongelap Atoll ...................................................................................................

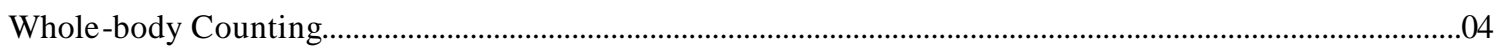

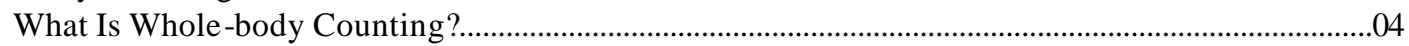

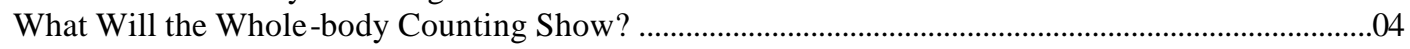

Estimating Doses from Cesium-137 Using Whole-body Counting .....................................................05

Internal Doses from Cesium 137 on Rongelap..........................................................................05

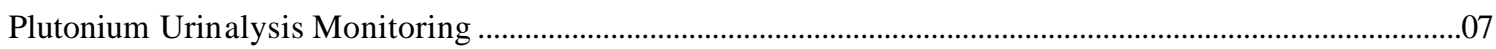

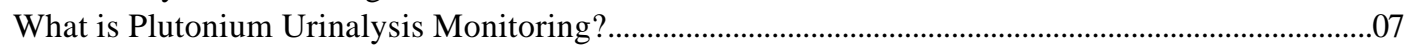

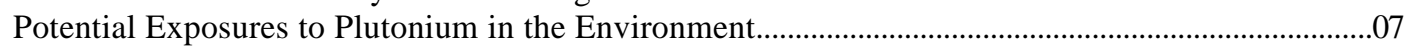

What is the Purpose of Plutonium Urinalysis in the Marshall Islands? .............................................07

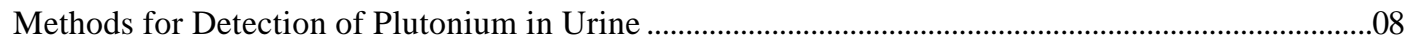

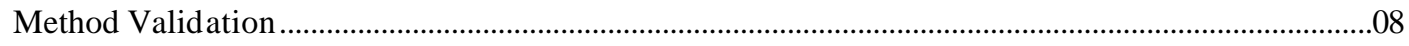

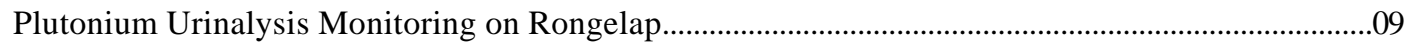

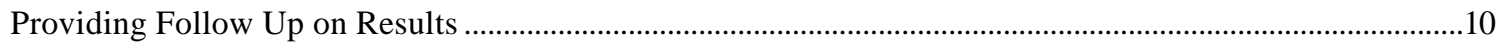

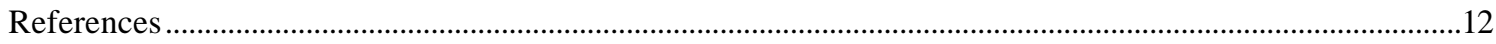

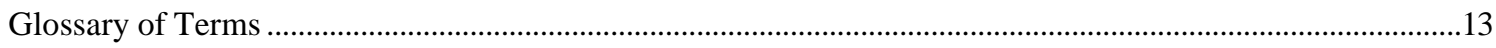

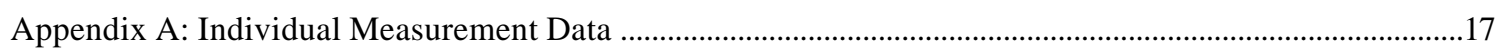

Table 1. Whole-body counting data for resettlement workers on Rongelap Island

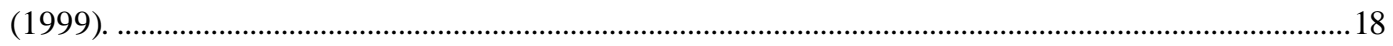

Table 2. Whole-body counting data for resettlement workers on Rongelap Island

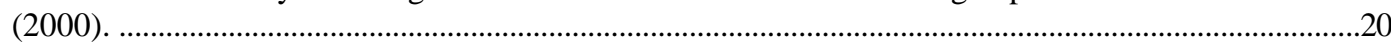

Table 3. Whole-body counting data for resettlement workers on Rongelap Island

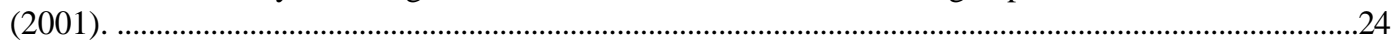

Table 4. Rongelap plutonium urinalysis data (1998-1999) from the University

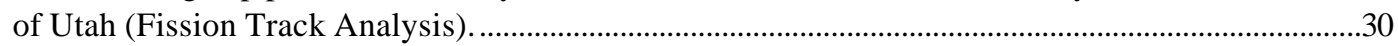

Table 5. Plutonium urinalysis data for resettlement workers on Rongelap Island

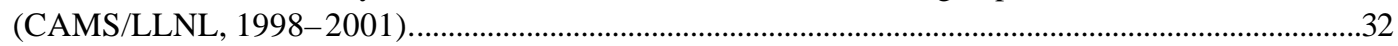

\section{List of Figures}

Figure 1. Whole-body counting facility on Rongelap Island. .01

Figure 2. Map of the Republic of the Marshall Islands showing the fallout pattern from the BRAVO test conducted on 1 March 1954.

Figure 3. Soil remediation on Rongelap Island... 
Figure 4. The Rongelap whole-body counter with a volunteer seated in the chair.

Figure 5. An assessment of cesium-137 exposure in resettlement workers on Rongelap Island (1999-2001) using whole -body counting...

Figure 6. Results of a NIST interlaboratory exercise on low-level Plutonium-239 determination in synthetic urine (microbecquerel, $\mu \mathrm{Bq}$ ).

Figure 7. Range and extent of plutonium excretion rates observed in resettlement workers from Rongelap Island (1998-2001).

Figure 8. An assessment of the projected 70-year lifetime dose from plutonium deposition in resettlement workers on Rongelap Island. 


\section{INTRODUCTION}

The United States (U.S.) Department of Energy (DOE) has recently implemented a series of strategic initiatives to address long-term radiological surveillance needs at former U.S. test sites in the Marshall Islands. The plan is to engage local atoll communities in developing shared responsibilities for implementing radiation protection programs for resettled and resettling populations. Using pooled resources of the U.S. Department of Energy and local atoll governments, individual radiation protection programs have been developed in whole-body counting and plutonium urinalysis to assess potential intakes of radionuclides from residual fallout contamination. The whole-body counting systems are operated and maintained by Marshallese technicians (Figure 1). Samples of urine are collected from resettlement workers and island residents under controlled conditions and analyzed for plutonium isotopes at the Lawrence Livermore National Laboratory (LNLL) using advanced accelerator based measurement technologies. This web site provides an overview of the methodologies, a full disclosure of the measurement data, and a yearly assessment of estimated radiation doses to resettlement workers and island residents.

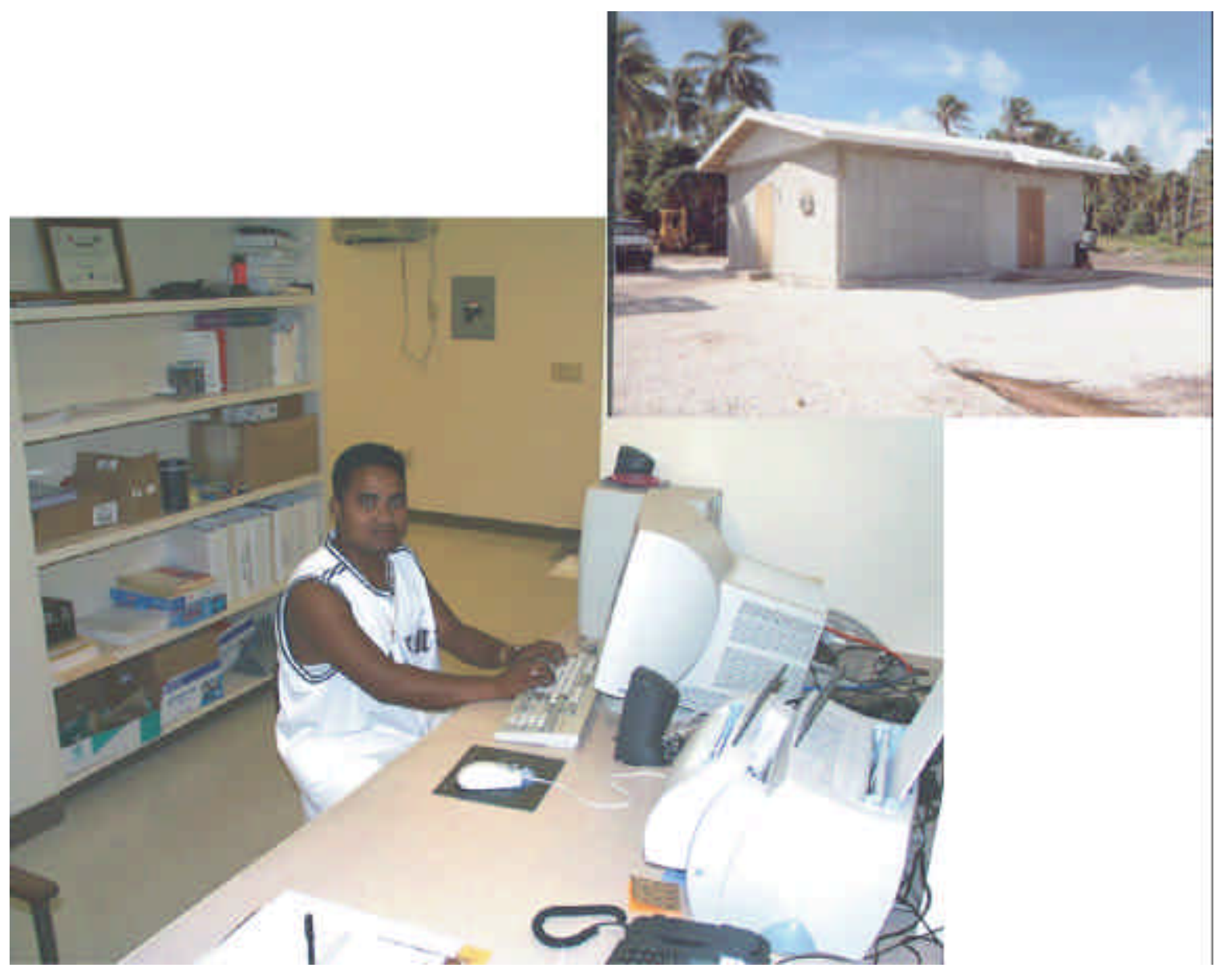

Figure 1. Whole-body counting facility on Rongelap Island 


\section{BRIEF HISTORY OF NUCLEAR TESTING IN THE MARSHALL ISLANDS}

\section{Introduction}

Immediately after WWII, the United States created a Joint Task Force to develop a nuclear weapons testing program. Planners examined a number of possible locations in the Atlantic, the Caribbean, and the Pacific but decided that coral atolls in the northern Marshall Islands offered the best advantages of stable weather conditions, fewest inhabitants to relocate, and isolation with hundreds of miles of open ocean to the west where trade winds were likely to disperse radioactive fallout. During the period between 1945 and 1958, there were a total of 67 nuclear tests conducted on Bikini and Enewetak Atoll in the Marshall Islands.

The most significant contaminating event was the Castle Bravo test conducted on March 1, 1954. Bravo was an experimental thermonuclear device with an estimated explosive yield of $15 \mathrm{MT}$ that led to widespread fallout contamination over the inhabited islands of Rongelap and Utirik Atolls as well as other areas to the east of Bikini (Figure 2). Today, the Department of Energy, through the Office of Health Studies, continues to provide environmental monitoring, healthcare, and medical services on affected atolls.

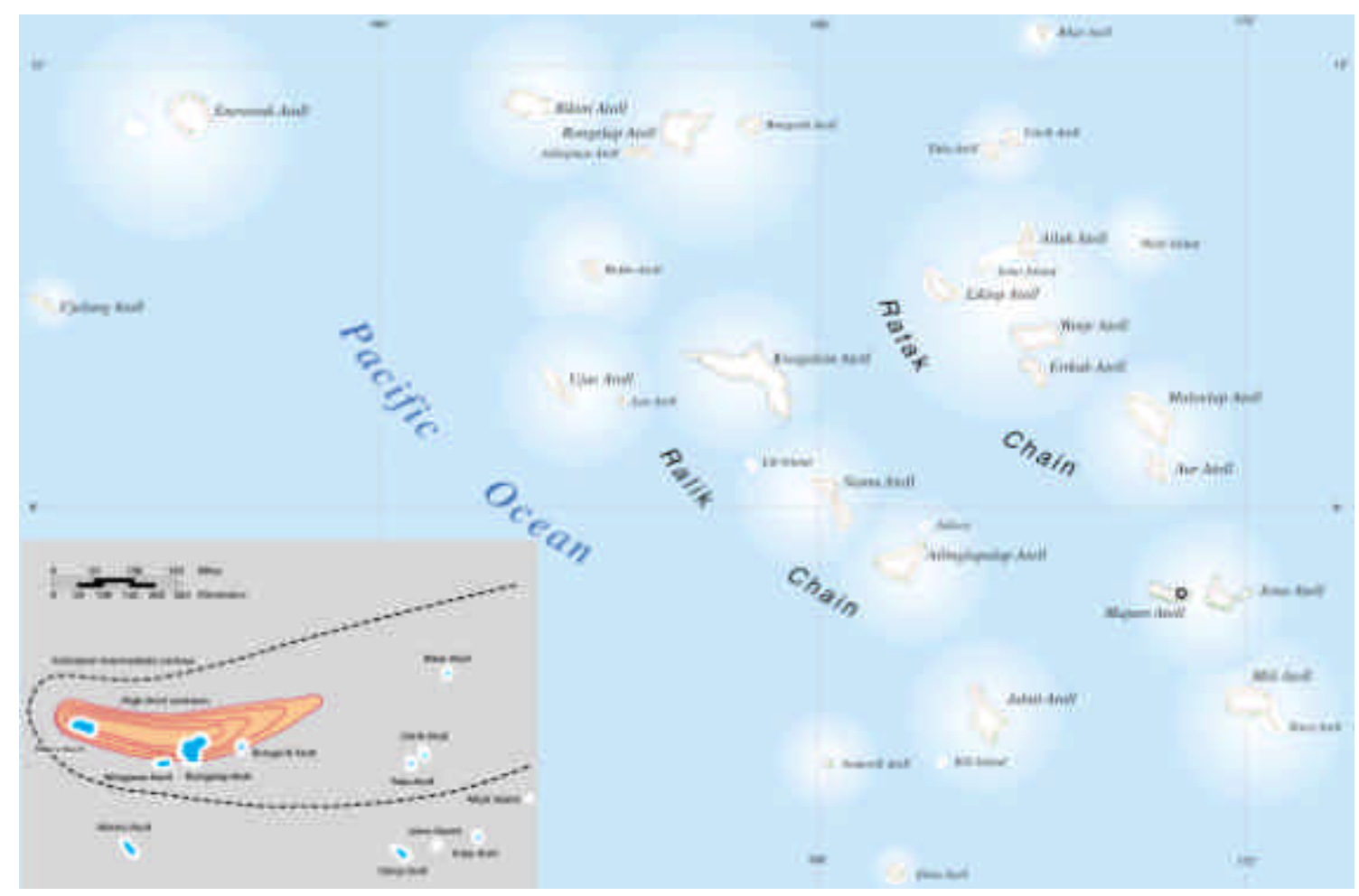

Figure 2. Map of the Republic of Marshall Islands showing the fallout pattern from the Bravo test conducted on 1 March 1954. 


\section{Rongelap Atoll}

People and Events on Rongelap Atoll

On March 1, 1954, the United States

conducted a nuclear test, code named 'Bravo,' on Bikini Atoll in the northern Marshall Islands that led to widespread fallout contamination over the inhabited islands of Rongelap and Utirik Atoll. Prior to Bravo, little consideration was given to the potential health and ecological impacts of fallout contamination beyond the immediate vicinity of the test sites. A total of 64 people living on Rongelap received significant exposure to radioactive fallout and had to be evacuated to Kwajalein Atoll for medical treatment. The Rongelap community spent the next 3 years living on Ejit Island (Majuro Atoll) before returning home to Rongelap in June of 1957. However, growing concerns about the possible health effects of exposure to residual fallout contamination on the island prompted residents to relocate to a new temporary home on Mejatto Island (Kwajalein Atoll) in 1985. The Rongelap people are still resident on Mejatto today, although part of the community has split off to live in Majuro and Ebeye.

The Rongelap community has always expressed a strong desire to return to their ancestral homeland. Through the Rongelap Resettlement Act, the U.S. Congress approved and continued a 1996 resettlement agreement between the United States and the Rongelap Atoll Local Government, extending distribution authority for ten years to advance resettlement. As a part of the 1996 resettlement agreement, a Phase I resettlement program was initiated in 1998. Rongelap leaders engaged the U.S. Department of Energy in developing a resettlement support plan to provide environmental monitoring to verify the effectiveness of cleanup methods, and to develop local resources and expertise in radiation protection monitoring. The U.S. Department of Energy, the Rongelap Atoll Local Government, and the Republic of the Marshall Islands have since signed a Memorandum of Understanding outlining shared provisions in support of resettlement (MOU, 1999).

\section{Resettlement of Rongelap Atoll}

Rongelap leaders have made significant progress in developing the necessary infrastructure to help foster and sustain a prosperous resettlement of Rongelap Island. Phase I resettlement activities have included the construction of a modern field station to accommodate workers and visitors, a power plant, reverse osmosis units and holding tanks to provide a clean source of fresh water, paved roads, an extended runway, and a new dock. Another key resettlement initiative was to reduce the level of radiation exposure on the island by employing a "combined cleanup option." This remediation technique has been very successfully applied in large-scale field experiments conducted on Bikini Island (Robison et al., 1994), and is expected to be equally effective on Rongelap. The combined option calls for limited soil removal, the addition of crushed coral fill in and around the village and housing areas (Figure 3 ) to reduce external radiation exposure, and the application of potassium chloride fertilizer in the agricultural areas to reduce the uptake of cesium- 137 into locally grown foods. The ingestion of cesium-137, contained in coconut, Pandanus fruit, and breadfruit, represents the main pathway for exposure of island residents to residual fallout contamination. The addition of potassium fertilizer competitively blocks cesium- 137 being taken up into the locally grown foods. It is expected that the addition of potassium fertilizer to agricultural areas on Rongelap will reduce the dose that people receive from ingestion of cesium 137 to less than $10-20 \%$ of the pretreatment level and, at the same time, help support plant growth, which will increase their productivity. 


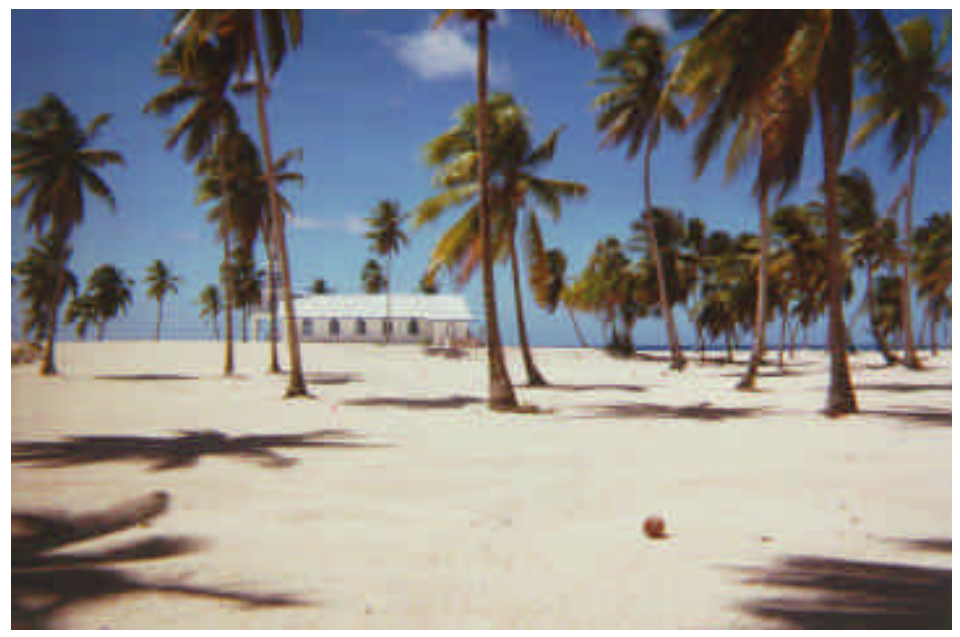

Figure 3. Soil remediation on Rongelap Island. Contaminated soil around the service and village area has been replaced with a layer of clean crushed coral to reduce the external exposure to cesium-137 and other sources of penetrating radiation present in the underlying soil. The initial phase of this work was completed in March 2001. A very detailed in-situ gamma radiation survey of the entire area, conducted during May 2001 by scientists from the Lawrence Livermore National Laboratory, concluded that the cleanup operation had been very successful. The average external dose from Cesium 137 within the service and village area was reduced by over 20 fold to less than 1 mrem per year. View full report, UCRL-ID-143680-Pt-1 (Hamilton et al., 2001).

\section{WHOLE-BODY COUNTING}

\section{What Is Whole-Body Counting?}

The whole-body counting systems installed in the Marshall Islands contain large volume sodium iodide radiation detectors that measure gamma rays coming from radionuclides deposited in the body. The system is modeled after the "Masse-Bolton Chair" design (Figure 4). It can be used to detect high-energy gamma emitting radionuclides, such as cesium-137, cobalt-60, and potassium-40, in most of the body and all of the internal organs. Using internationally accepted methods, the total amount of a radionuclide measured by wholebody counting is converted into a dose estimate using specially designed computer software (Canberra, 1998a, 1998b ).

The whole-body counting system is calibrated using a human surrogate calibration source, called a Bottle Man-akin Absorption (BOMAB) phantom, filled with a known amount of a mixed gamma-emitting standard traceable to the U.S. National Institute of Standards and Technology. Background and other quality control check counts are performed on a daily basis to ensure that the system conforms to applicable quality requirements.

Local Marshallese technicians are responsible for all daily operations in the wholebody counting facilities. Each technician receives an initial six weeks of intensive training and periodic retraining at the Lawrence Livermore National Laboratory and is employed to run the facility for up to 40 hours per week. Scientists from the Lawrence Livermore National Laboratory provide on-going technical assistance, advanced training, and perform a more detailed data quality assurance appraisal before the data is released or posted to this web site.

\section{What Will the Whole-Body Counting Show?}

The main pathway for exposure to residual fallout contamination in the northern Marshall Islands is through ingestion of cesium137 contained in locally grown foods, such as 


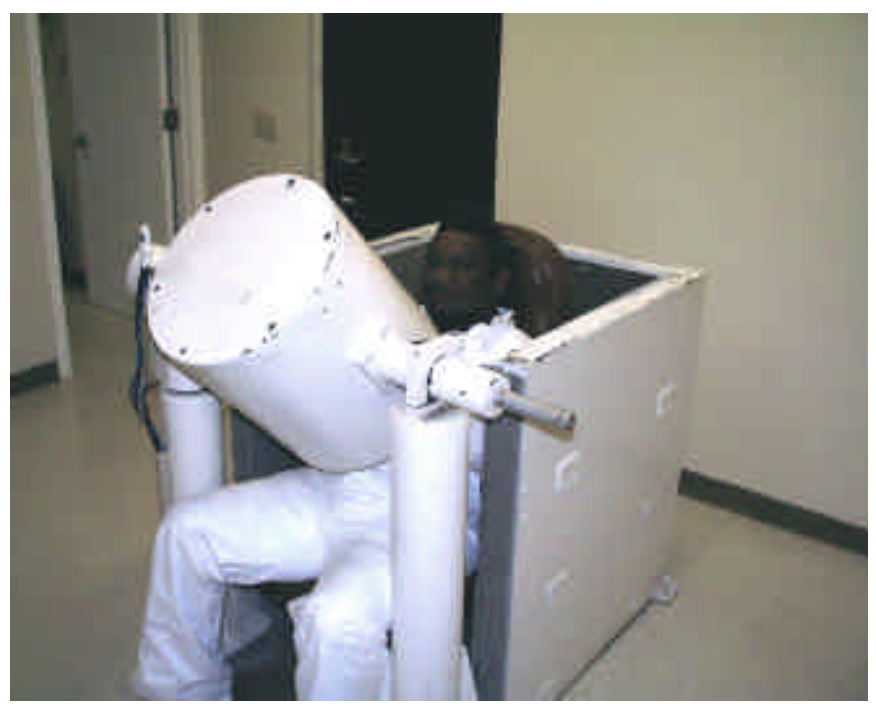

Figure 4. The Rongelap whole-body counter with a volunteer seated in the chair.

coconut, Pandanus fruit, and breadfruit. Wholebody counting is a simple and effective method of determining the quantity of gamma emitters in the body. The whole-body counting program in the Marshall Islands will offer island residents an unprecedented level of protection until it is clearly demonstrated that radiation surveillance measures can be relaxed. The value of this type of radiation protection monitoring program lies in the fact that the whole-body count data provides a direct measure of the full range of radionuclide intakes in the local populations. Information about in dividual intakes and potential 'high-end' health risks can be assessed from the measurement data rather than relying on assumptions based on a range of assumed intake scenarios. In combination with environmental monitoring data, residents who receive a wholebody count showing the presence of cesium-137 can make an informed decision about their eating habits and/or lifestyle based on what is considered a 'safe' or acceptable health risk. The Marshall Islands Government has adopted a very stringent cleanup dose standard of 15 mrem per year (0.15 millisievert per year) as an acceptable level of exposure. As communities return to their native islands, whole-body counting will provide a level of reassurance that radiation related health risks remain at or below these established standards.

\section{Estimating Doses from Cesium-137 Using Whole-body Counting}

People living in the Marshall Islands may be exposed to cesium- 137 taken up from the soils into locally grown foods. Whole-body counting provides a direct measure of the amount of cesium-137 inside the body of people. The biokinectic behavior of cesium 137 in the human body is well known and allows information from the whole-body counter to be converted to a radiation dose. The radiation dose is the quantity used by health physicists to estimate radiation induced health risks. Dose estimates provided on this web site are expressed as an annual or projected 70-year lifetime dose, assuming a chronic exposure to cesium-137 and/or plutonium-239.

\section{Internal Doses from Cesium-137 on Rongelap}

The whole-body counting data are shown in Tables 1, 2, and 3 of Appendix A.

The annual internal effective dose from cesium-137 to resettlement workers on Rongelap Atoll between 1999-2001 is presented in graphical form on a frequency distribution bar chart (Figure 5). 


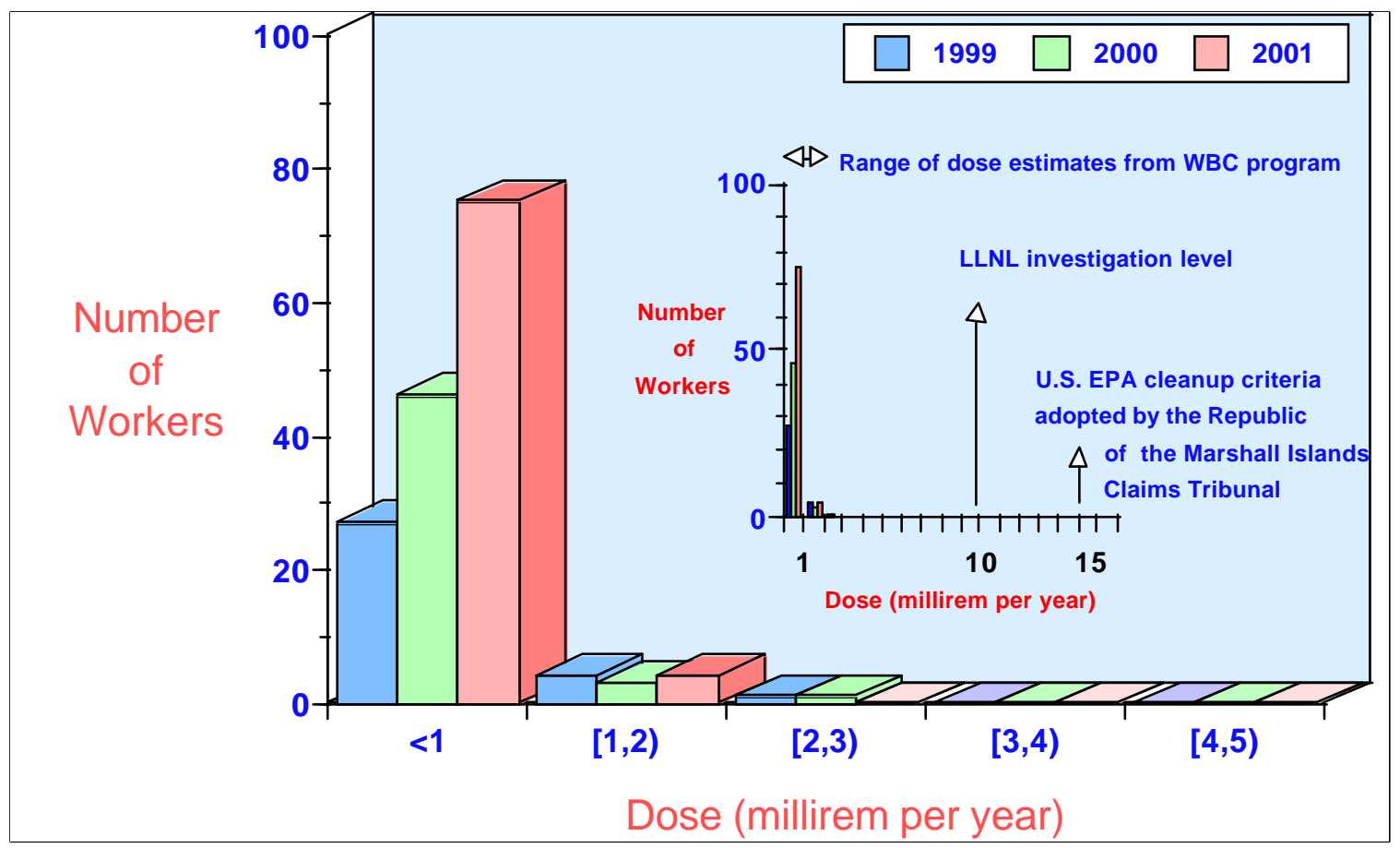

Figure 5. An assessment of cesium-137 exposure in resettlement workers on Rongelap Island (1999-2001) using whole-body counting.

The majority of resettlement workers on Rongelap Island received an annual internal dose from cesium 137 of less than $1 \mathrm{mrem}$. The average individual dose for the worker population was $0.5 \pm 0.6 \mathrm{mrem}$ per year in 1999 (32 individuals), $0.4 \pm 0.5$ mrem per year in 2000 (50 individuals), and $0.2 \pm 0.3$ mrem per year in 2001 (79 individuals). Annual dose estimates can be compared with a natural background dose of 140 mrem per year in the Marshall Islands and
300 mrem per year in the United States.

The annual doses observed on Rongelap Island are well below the recommended dose limit for members of the public in the United States of 100 mrem per year from radiological sources. Under present living conditions, the observed doses indicate resettlement workers are receiving adequate radiation protection from residual fallout contamination. 


\section{PLUTONIUM URINALYSIS MONITORING}

\section{What Is Plutonium Urinalysis Monitoring?}

Plutonium urinalysis is a very sensitive measurement technique used to determine the amount of plutonium in human urine as a means of estimating human exposure to plutonium. Plutonium urinalysis tests are performed by collecting urine from individuals over a 24 -hour period. The test turns a urine sample into a powder, which scientists then analyze by counting the number of plutonium atoms in the sample, using mass spectrometry. Everybody has a small amount of plutonium in their bodies from exposure to worldwide fallout contamination. The amount of plutonium detected in the Marshall Islands can be compared with baseline excretion rates to assess likely intakes associated with resettlement.

The Marshall Islands urinalysis program uses a state-of-the-art measurement technology available at the Center for Mass Spectrometry at the Lawrence Livermore National Laboratory. Accelerator mass spectrometry is about 100 times more sensitive than monitoring techniques commonly employed in occupational monitoring programs within the United States.

\section{Potential Exposures to Plutonium in the Environment}

Plutonium is an important radioactive element produced in nuclear explosions. Plutonium emits alpha particles (or alpha-rays). Alpha particles are heavy, slow moving, charged particles that travel only one or two inches in air and can be stopped by a piece of paper or the dead, outside layers of our skin. Therefore, any possible health effects from plutonium come from internal exposure.

Persistent and measurable quantities of residual fallout plutonium contamination have been observed in soils from test sites in the northern Marshall Islands. However, plutonium is not readily transferred from soils to plants (for example, the concentration of plutonium in vegetation is about 100,000 times less than in associated soil) nor is there significant gastrointestinal adsorption of plutonium through the gut of animals and/or marine organisms.

The main potential exposure pathway for plutonium is from inhalation of contaminated dust particles in the air that people breath. Inhaled or ingested plutonium may eventually end up in various tissues - especially the lungs, liver and bone-resulting in continuous exposure of these tissues to alpha particle radiation. Plutonium remains in the body for a long time, but the systemic uptake and associated dose contribution from plutonium in people living on Enewetak and Rongelap Islands are still expected to be low (Harrison et al, 1989; ICRP, 1986, 1990, 1993, 1994).

Potential radionuclide inhalation exposure rates due to resuspension of contaminated soil can be estimated from the product of the soil concentration, resuspension enhancement factors, and inhalation dose factors for the various radionuclides. These estimates show that the projected dose contribution from residual plutonium on Enewetak and Rongelap Islands will be less that $5 \%$ of the total manmade dose over a lifetime. Dose estimates from environmental data are also consistent with results from previous urinalysis studies conducted in the Marshall Islands by the Brookhaven National Laboratory.

\section{What Is the Purpose of Plutonium Urinalysis in the Marshall Islands?}

Plutonium urinalysis is a measurement technique that ultimately provides information to individuals on the amount of plutonium they have in their bodies. Although plutonium is expected to be a minor contributor to the total man-made dose, it is a concern to people living in the northern Marshall Islands who are potentially exposed to elevated concentrations of plutonium in the environment. Consequently, the U.S. Department of Energy agreed to monitor resettlement workers and perform a limited number of urinalysis tests on island residents, using advanced measurement technologies available at the Lawrence Livermore National Laboratory. 
The Marshall Islands plutonium urinalysis monitoring program was designed to address the following issues:

1) To provide more reliable and accurate data to assess baseline and significant incremental intakes of plutonium in the resettled and resettling populations using advanced accelerator based mass spectrometric measurement technologies.

2) To monitor the levels of plutonium exposure in critical populations groups, such as workers engaged in soil remediation or agriculture.

3) To demonstrate and document that occupational and/or public exposures to plutonium are below levels that will impact human health.

4) To participate in analytical proficiency testing programs to ensure that the accuracy and reliability of the measurements meet all applicable quality requirements.

5) To document and test the reliability of using environmental data to assess plutonium exposures to people living on coral atolls.

\section{Methods for Detection of Plutonium in Urine}

The decision to support a Marshall Islands plutonium urinalysis monitoring program at the Lawrence Livermore National Laboratory was originally made in 1998 . Urine samples were initially sent to the University of Utah for analysis of plutonium, using fission track analysis. Fission is a process where heavy nuclei, such as plutonium and uranium, break up into two large fragments. Fission may occur spontaneously or be induced by collisions with neutrons.

During fission track analysis, samples are exposed to a source of neutrons in a reactor, in contact with a quartz or plastic slide. Any resulting fission fragments leave behind tracks on the slide that can be counted under an optical microscope to determine the amount of plutonium present. Historically, fission track analysis has been plagued with a number of deficiencies including the use of less than reliable and tedious preparative methods, low chemical yields, contamination issues, and inaccurate quantification. The University of Utah and the Brookhaven National Laboratory improved on the fission track process methodology and adopted a more rigorous approach to data reduction and quality assurance.

More recently, scientists from the Lawrence Livermore National Laboratory have developed an ultra low-level detection technique for determination of plutonium isotopes in urine using accelerator mass spectrometry. Accelerator mass spectrometry has a detection sensitivity around 1 to $3 \mu \mathrm{Bq}$ of plutonium and avoids many of the disadvantages of using either conventional atom counting techniques, such as alpha spectrometry and/or other competing new technologies.

There are two main isotopes of plutonium in the environment-plutonium-239 and plutonium-240. The isotopic composition of plutonium (i.e., the relative amounts of plutonium-239 and plutonium-240) vary significantly, depending on the origin of the plutonium. For example, the plutonium-240 content of local fallout produced in high yield nuclear tests in the Marshall Islands is significantly higher $\left({ }^{240} \mathrm{Pu} / 239 \mathrm{Pu} 0.25-0.35\right)$ than that contained in global fallout $\left({ }^{240} \mathrm{Pu} /{ }^{239} \mathrm{Pu} \sim 0.18\right)$ or in unfissioned nuclear fuel $\left({ }^{240} \mathrm{Pu} /{ }^{239} \mathrm{Pu} 0.05\right)$. Consequently, it may be possible to use urinalysis and plutonium isotope measurements as an investigative tool to assess exposures to Bravo or other specific test events.

The higher level of plutonium-240 in nuclear fallout also needs to be considered in dose estimates. It should also be noted that alpha spectrometry is a much less sensitive measurement technique and, along with fission track analysis, cannot distinguish between plutonium-239 and plutonium-240.

\section{Method Validation}

Method validation is the process used to monitor and document the quality of measurement data. The Lawrence Livermore National Laboratory has recently demonstrated the viability of using accelerator mass spectrometry for ultra-trace plutonium isotope detection and measurement. Method validation has included the successful participation of LLNL in an interlaboratory exercise organized by the U.S. National Institute of Standards and Technology. The results of this exercise clearly show that accelerator mass spectrometric technologies are well suited for detection of $\mu \mathrm{Bq}$ 


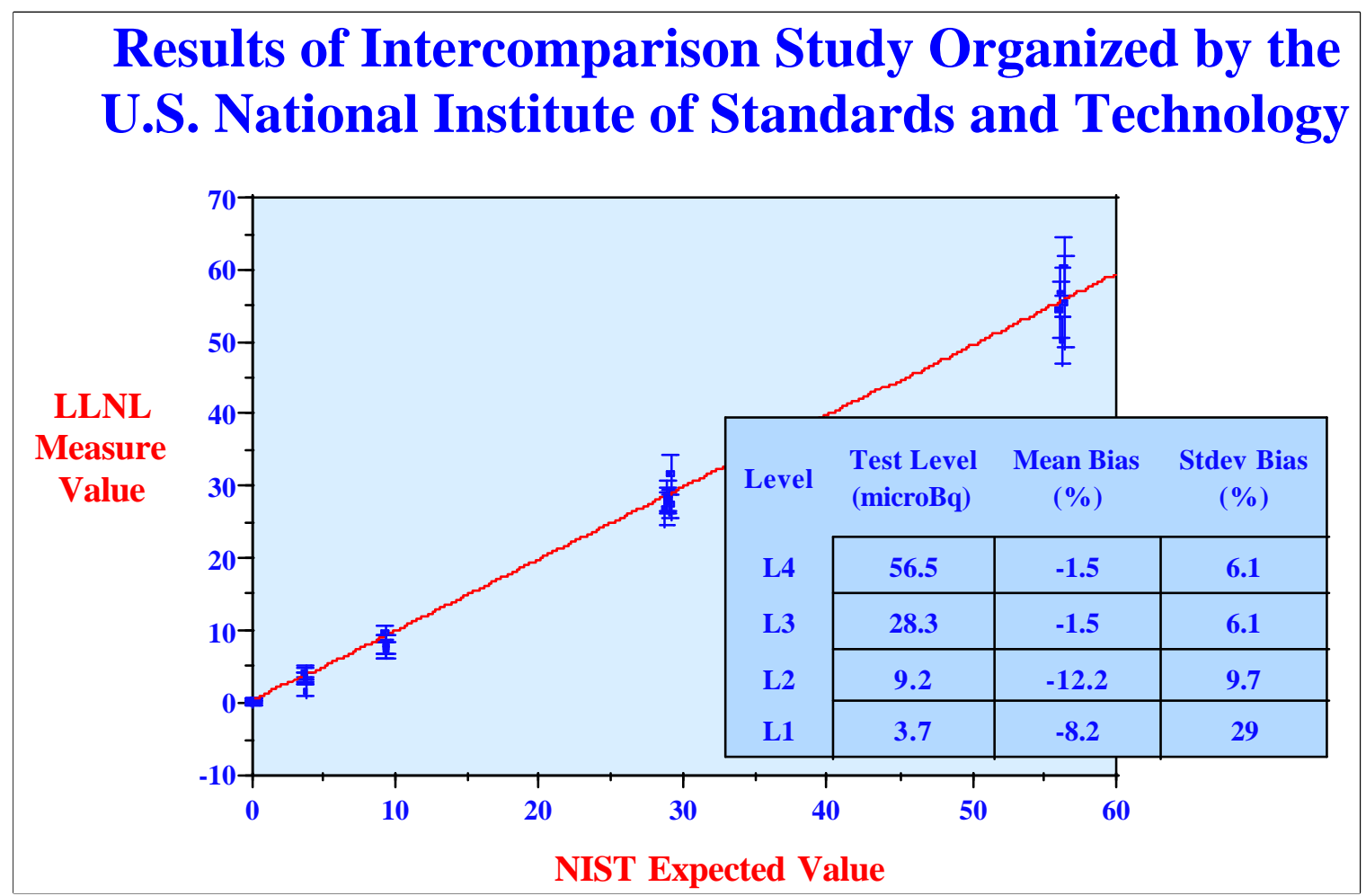

Figure 6. Results of a NIST interlaboratory exercise on low-level plutonium 239 determination in synthetic urine (microbecquerel, $\mu \mathrm{Bq}$ ).

concentrations of plutonium-239 and plutonium 240 in urine (Figure 6). View full report, UCRLID-147972 (Marchetti et al., 2001).

\section{Plutonium Urinalysis Monitoring on Rongelap}

The urinalysis data are shown in Tables 4 and 5 of Appendix A.

Figure 7 shows the frequency distribution of urinary excretion of plutonium by resettlement workers on Rongelap Island between 1998 and 2001. The apparent decrease in plutonium excretion over time appears to be an artifact of the accuracy and precision of the measurement technique employed. Early measurements performed by fission track analysis show a much broader range of values compared with accelerator mass spectrometry. Accelerator mass spectrometry enables monitoring of plutonium excretion down to 1 to $3 \mu \mathrm{Bq}$ per 24 hours. The improved sensitivity and reliability of this measurement technique was required in order to more ably assess potential low-level chronic exposures to plutonium in excess of baseline excretion resulting from previous exposures to general worldwide environmental contamination. However, the urinary excretion of plutonium by Rongelap resettlement workers during the past two years still far below a level where the measurements could be performed with an acceptable level of uncertainty. Moreover, the majority of the results fall below the critical level of the measurements.

This would normally negate the need to report a dose value at all; rather, we would assume the dose from plutonium was zero. For completeness, we have included dose estimates in our reporting.

The projected 70 -year lifetime dose from internally deposited plutonium in the worker population is less than 10 mrem (or $0.1 \mathrm{mSv}$ ), well below applicable cleanup standards (Figure 8). 


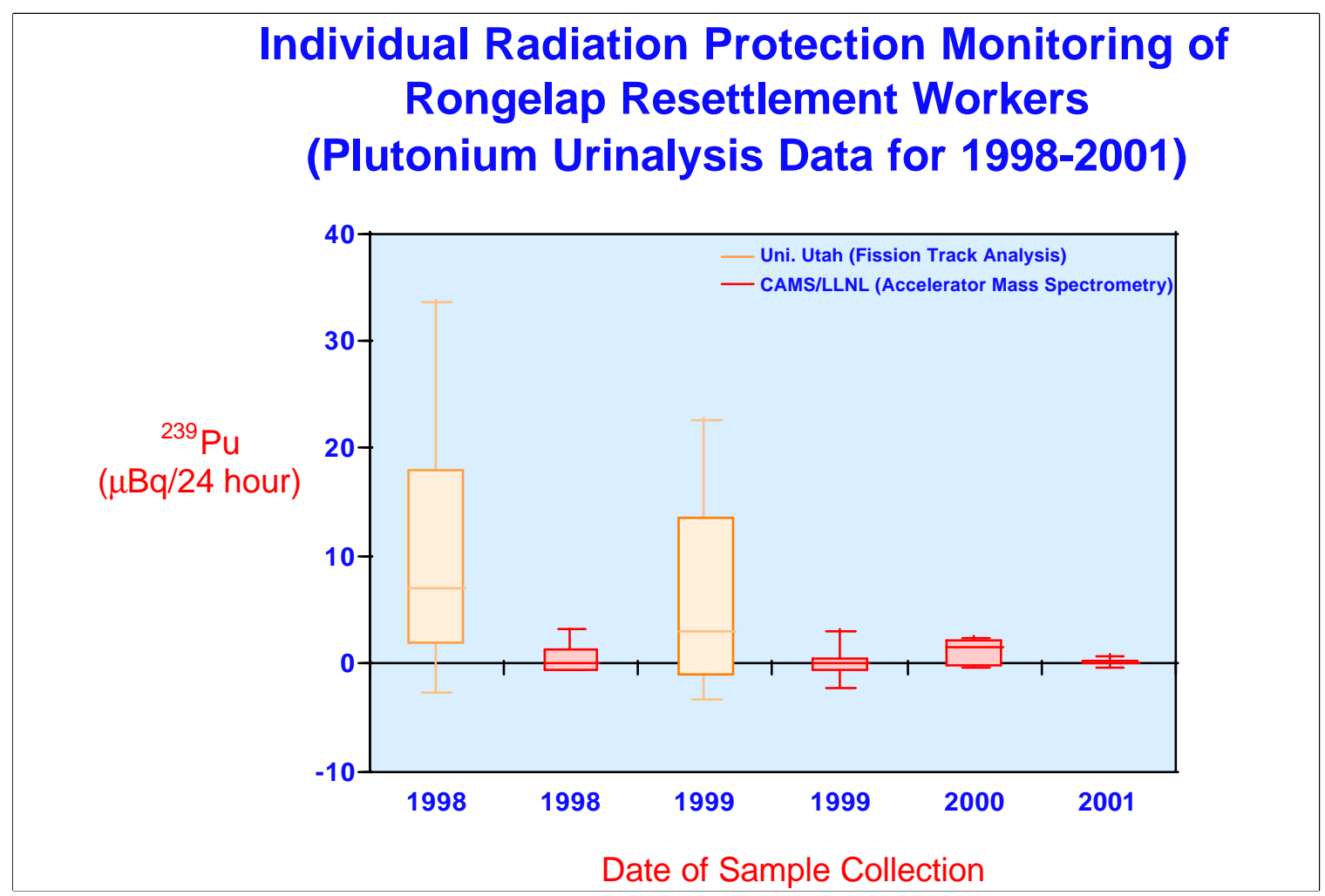

Figure 7. Range and extent of plutonium excretion rates observed in resettlement workers from Rongelap Island (1998-2001). The data is expressed in microBecquerel $(\mu \mathrm{Bq})$ per 24 hour urine sample. The box encompasses the 25 th and 75 th percentile while the whiskers represent the 10th and 90th percentile range. The median value is represented by the bar line.

Urinary excretion of plutonium by Rongelap resettlement workers will consist of a baseline, long-term excretion from residual systemic burdens acquired from all previous exposures and a potential prompt-excretion component from any intake associated with resettlement. Dose estimates, shown here, assume that the intake of plutonium is equivalent to the daily excretion rate, i.e., that the total body burden of plutonium will be remain at the present level. This is a very conservative (i.e., dose maximizing) assumption. There is no evidence of significant incremental intakes of plutonium above what might be expected from residual systematic burdens of plutonium acquired from previous exposures to worldwide fallout contamination. Previous estimates of the background urinary excretion of plutonium in adults from the northern Marshall Islands range from 1-2 $\mu \mathrm{Bq}$ per 24-hour urine sample (NRC, 1994).

\section{PROVIDING FOLLOWUP ON RESULTS}

All program volunteers receive a preliminary copy of their dose report immediately after they receive a whole-body count. Scientists from the Lawrence Livermore National Laboratory verify the measurements, and if required, a revised dose report is generated and returned to the individuals concerned. Annual doses of 10 mrem or above evoke a predetermined action or investigation. These actions may include follow-up measurements, a dietary evaluation, and/or a work history review. Below this level, we assume that default 
assumptions for assigning doses are valid and need not be considered for investigation of intake. This action level is one-tenth of the investigation level used throughout the Department of Energy and is well below the 15 mrem cleanup standard adopted by the Marshall
Islands. In addition, at the end of each calendar year, all program volunteers receive a final written report containing all available verified individual whole-body counts and plutonium urinalysis measurement data along with their estimated annual or projected lifetime doses.

\section{ACKNOWLEDGMENT}

This work was performed under the auspices of the U. S. Department of Energy by the University of California, Lawrence Livermore
National Laboratory under Contract No. W7405-Eng-48.

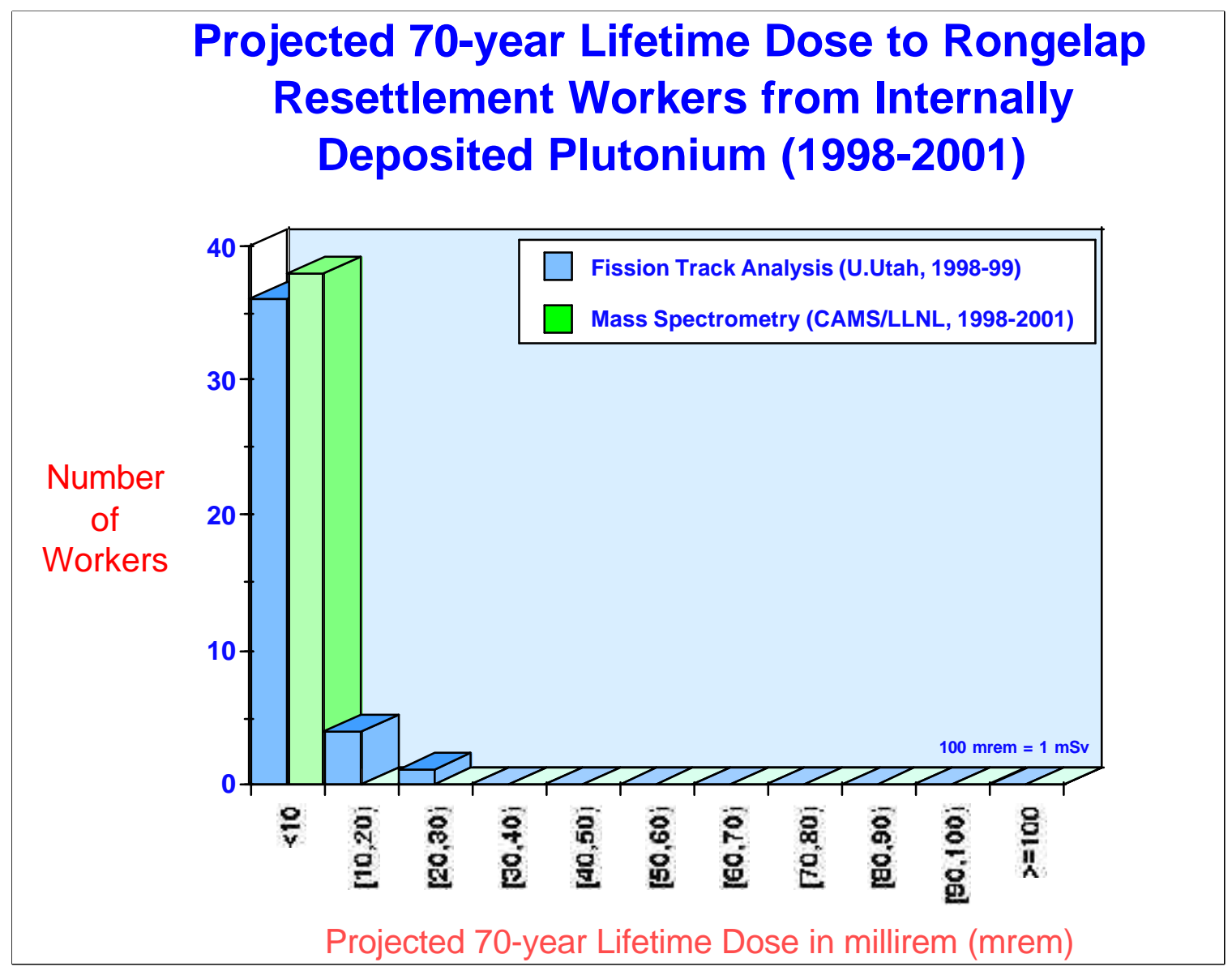

Figure 8. An assessment of the projected 70-year lifetime dose from plutonium deposition in resettlement workers on Rongelap Island (1998-2001). 


\section{REFERENCES}

Canberra Industries (1998a), Abacos-2000, Canberra Industries, Meriden, CT.

Canberra Industries (1998b), Genie-200 Spectroscopy System, Canberra Industries, Meriden, CT.

Hamilton, T., S. Kehl, J. Brunk, F. Gouveia, W. Robison (2001), Rongelap Resettlement Support-Preliminary Report Part 1: In-Situ Gamma Spectrometric Measurements around the Service and Village Area on Rongelap Island, Lawrence Livermore National Laboratory, Livermore, CA, UCRL-ID-143680-Pt.-1, pp.16.

Harrison, J. D., G. P. L. Naylor, and J. W. Stather (1989), Gastrointestiral Absorption of Plutonium and Americium in Rats and Guineapigs after Ingestion of Dusts from the Former Nuclear Weapons Test Site at Marolinga: Implications for Human Exposure, National Radiation Protection Board, NRPB-M196.

International Commission on Radiological Protection (ICRP) (1986), The Metabolism of Plutonium and Related Compounds, Oxford: Pergamon Press, Publication 48.

International Co mmission on Radiological Protection (ICRP) (1990), Age-Dependent Doses to Members of the Public from Intake of Radionuclides: Part 1, New York: Pregamon Press, Publication 56.

International Commission on Radiological Protection (ICRP) (1993), Age-Dependent Dose to Members of the Public from Intake of Radionuclides: Part 2 Ingestion Dose Coefficients, New York: Pregamon Press, Publication 67.
International Commission on Radiological Protection (ICRP) (1994), Human Respiratory Tract Model for Radiological Protection, New York: Pergamon Press, Publication 66.

Marchetti, A.A., T.A. Brown, J.E. McAninch, J. Brunk, C.C. Cox, R.E. Martinelli, J.P. Knezovich, and T.F. Hamilton (2002), Measurement of Plutonium Isotopes in Urine at Microbecquerel Levels: AMS Results of a NIST Interlaboratory Exercise, Lawrence Livermore National Laboratory, Livermore, CA, UCRL-ID-147972.

Memorandum of Understanding (MOU) (1999) by and between the Republic of the Marshall Islands, the Rongelap Atoll Local Government Council, the U.S. Department of Energy, Office of Environmental Safety and Health, and the U.S. Department of the Interior, Office of Territorial and International Affairs for the Rongelap Resettlement Project.

NRC (1994), Radiological Assessments for Resettlement of Rongelap in the Republic of the Marshall Islands, National Research Council, National Academy Press, Washington DC, 1994, 108 pp.

Robison, W. L., C. L. Conrado, K. T. Bogen (1994), An Updated Dose Assessment for Rongelap Island, Lawrence Livermore National Laboratory, Livermore, CA, UCRL-LR-107036, pp. 59. 


\section{GLOSSARY OF TERMS}

\author{
Absorbed Dose \\ The absorbed dose is the energy \\ deposited in an organ or tissue per unit mass of \\ irradiated material. The common unit for \\ absorbed dose is the rad, which is equivalent to \\ 100 egs per gram of material. \\ The international scientific community \\ has adopted the use of a different term for rad \\ called a gray (Gy). One Gy is the same as 100 \\ rad.
}

\section{Activity}

The transition rate or number of radioactive decays per unit time of a given radioactive source expressed in units of becquerel, curie or other acceptable units.

\section{$\underline{\text { Alpha Particles }}$}

Alpha particles are one of the primary types of radiation associated with radioactivity. Alpha rays are heavy, slow moving, charged particles that travel only one or two inches in air and can be stopped by a piece of paper or the dead, outside layers of skin. Because of the very short range of the emitted alpha radiation, the main concern in radiation protection is from the potential health effects of internally deposited alpha-emitting radionuclides.

\section{$\underline{\text { Background Radiation }}$}

The average person in the United States receives about 360 mrem of ionizing radiation every year. About 300 mrem per year comes from natural background radiation from outer space, soil and air that people breath, and about 60 mrem from man-made sources such as medical exposures to diagnostic rays and consumer products (e.g., from smoking tobacco). The general worldwide contribution from radioactive fallout contamination is $<0.3 \%$ of the average total dose. Exposures to natural background radiation vary depending on the geographic area, diet, and factors such as the composition of materials used in the construction of homes. The natural background radiation dose in the Marshall Islands is around 140 mrem per year and is significantly less than what most people receive around the world.

\section{Baseline}

We have all been exposed to some level of worldwide fallout contamination. In the United States, it is estimated that the population receives up to 1.5 millirem ( $0.3 \%$ of the average total annual dose) from worldwide fallout and about 0.5 millirem (or $0.1 \%$ of the average total annual dose) from operations related to nuclear power generation. Similarly, people living in the Marshall Islands will have very small quantities of internally deposited plutonium and cesium137 in their bodies from worldwide environmental contamination of food, air, water and soil. The residual system burden acquired from previous exposures provides a baseline for assessing the significance of any intake associated with resettlement.

Our measurements show that the baseline urinary excretion of plutonium by resettlement workers on Rongelap and the resident population on Enewetak is at or below the sensitivity of our measurements by accelerator mass spectrometry.

Whole-body counting will also be used to establish the cesium-137 baseline for the Rongelap population as resettlement begins. The aim of the Marshall Islands radiation protection monitoring program is to monitor internally deposited radionuclide that fall above the existing baseline and may potentially be associated with resettlement.

For the purposes of this discussion, the urinary excretion of plutonium must increase by about $3 \mu \mathrm{Bq}$ per day to register a positive detection at a reasonable level of uncertainty. Therefore, the minimal detectable dose for the plutonium urinalysis program is around 0.02 mrem per year.

Similarly, the Minimum Detectable Amount (MDA) for the whole -body counting systems on Rongelap and Enewetak range from $\sim 0.04$ to $0.2 \mathrm{kBq}$. This translates into a detectable annual effective dose of around 0.2 to 0.7 mrem.

\section{$\underline{B e c q u e r e l}(\mathrm{~Bq})$}

A Becquerel (abbreviated as Bq) is the International System (SI) unit for the activity of 
radioactive material. One $\mathbf{B} \mathbf{q}$ of radioactive material is that amount of material in which one atom is transformed or undergoes one disintegration every second. The common units used in this report for reporting whole-body counting and plutonium urinalysis data are the $\mathbf{k B q}(\mathrm{kiloBq})$ and $\mu \mathbf{B q}$ (microBq).

\section{Biokinectic}

The word 'biokinectic' is used here to describe the adsorption (uptake), distribution and retention of elements in humans.

\section{Calibration}

The process of adjusting, determining the response, or reading an instrument to a standard.

\section{Committed Dose Equivalent}

The time integral of the dose-equivalent rate in an organ or tissue that will be received by an individual following an intake of radioactive material into the body. When the time integral is not specified, it will be taken as 50 years for adults and to age 70 years for intakes by children. Committed dose equivalent is normally expressed in units of rem.

The international scientific community has adopted the use of a different term for rem called a sievert $(\mathrm{Sv})$. One $\mathrm{Sv}$ is the same as 100 rem.

\section{Committed Effective Dose Equivalent}

The committed dose equivalents to various tissues or organs in the body each multiplied by an appropriate tissue-weighing factor and then summed. Committed effective dose equivalence (CEDE) is normally expressed in units of rem.

The international scientific community has adopted the use of a different term for rem called a sievert $(\mathrm{Sv})$. One $\mathrm{Sv}$ is the same as 100 rem.

\section{Critical Level}

The amount of a count $\left(\mathrm{L}_{\mathrm{c}}\right)$ or final measurement of a quantity of an analyte at or above which a decision is made that the analyte is definitely present $\left(\mathrm{L}_{\mathrm{c}} \approx \mathrm{MDA} / 2\right)$

\section{Default Assumptions (used in assignment of dose)}

The largest contribution to the radiation dose attributable to residual nuclear fallout in the Marshall Islands results from either internal exposure from intake of radionuclides through ingestion, inhalation and/or absorption through the skin, and external exposure from radionuclides distributed in the soil. External exposure rates can be measured directly using instrument surveys of the radiation field. The assignment of dose to internally deposited radionuclides is much more complicated.

Biokinectic and dosimetric models developed by the International Commission on Radiological Protection (ICRP) are used to convert wholebody burdens (from whole-body counting or from in vitro bioassay tests, such as urinalysis) into dose. In the case of a chronic exposure, organ and body burdens continue to build up over time until a steady state is reached where losses due to decay and excretion are balanced by intake and absorption. Cesium 137 has an effective half-life in an adult of about 110 days and, under chronic exposure conditions, reaches a maximal dose rate after about 2 years. By contrast, plutonium absorbed from the gastrointestinal or respiratory tract enters the blood stream and deposits in liver and bone with an effective half-life of 20-50 years. Only a small fraction of plutonium entering the blood stream is excreted in urine with the long-term excretion rate approaching $2 \times 10^{-5}$ of the systemic body burden per day. Knowledge of excretion rates and time of exposure are important when interpreting urinalysis data.

\section{$\underline{\text { Direct bioassay }}$}

The measurments of radioactive material in the human body, utilizing instrumentation that detects radiation emitted from radioactive material in the body (synonymous with in vivo measurements)

\section{Dose Assessment}

The scientific process used to determine radiation dose and uncertainty in the dose.

\section{Dose Equivalent}

The dose equivalent is the adsorbed dose multiplied by a biological effectiveness 
factor for the radiation to cause biological damage. Dose equivalents are typically expressed in rem. A dose of 100 rem to an adult normally produces some clinical signs of radiation sickness and requires hospitalization.

The international scientific community has adopted the use of a different term for rem called a sievert $(\mathrm{Sv})$. One $\mathrm{Sv}$ is the same as 100 rem.

\section{Effective Dose Equivalent}

The effective dose equivalent for the whole-body is the sum of dose-equivalents for various organs in the body weighted to account for different sensitivities of the organs to radiation. It includes the dose from radiation sources internal and/or external to the body. The effective dose equivalent is usually expressed in units of millirem (mrem).

The international scientific community has adopted the use of a different term for millirem called a millisievert $(\mathrm{mSv})$. One $\mathrm{mSv}$ is the same as 100 mrem.

\section{External Dose or Exposure}

That portion of the dose equivalent received from radiation sources outside the human body.

\section{Fission Track Analysis}

During neutron irradiation, heavy nuclei, such as uranium and plutonium, undergo nuclear fission with release of large fission fragments. This property has led to the development of a number of measurement techniques such as delayed neutron activation analysis and fission track analysis. Fission track analysis is a measurement technique commonly employed in plutonium urinalysis (bioassay) monitoring programs. Urine samples are chemically treated to remove plutonium. The plutonium is then mounted in contact with a special plastic or quartz slide known as solidstate nuclear track detector (SSNTD). The slide, along with the sample, is then irradiated in a reactor where neutron-induced fission of plutonium-239 (or uranium-235) causes emission of energetic fission fragments. Some of the fragments penetrate into the SSNTD damaging the integrity of the material before coming to rest. The SSNTD is separated from the sample and chemically etched to expose the damaged areas (known as fission tracks) on the detector surface. The fission tracks are then counted under an optical microscope. The amount of plutonium (and/or uranium) present in the sample is a function of the total number of tracks and the neutron flux.

\section{Gamma-rays}

Gamma-rays are electromagnetic waves produced by spontaneous decay of radioactive elements. Sunlight also consists of electromagnetic waves, but gamma -rays have a shorter wavelength and much higher energy. High energy gamma-rays, such as those produced by decay of cesium-137, may penetrate deeply into the body and affect cells. Gamma rays from a cobalt-60 source are often used for cancer radiotherapy.

\section{High-End Health Risk}

Relates to the maximally exposed individuals in a population.

\section{$\underline{\text { In Vitro }}$}

In vitro measurements are synonymous with indirect bioassay techniques, such a urinalysis.

\section{$\underline{\text { In Vivo }}$}

In vivo measurements are synonymous with direct bioassay techniques, such wholebody counting.

\section{Indirect bioassay}

Measurements to determine the presence of or estimate the amount of a radioactive material in the excreta, urine or in other biological materials removed from the body (synonymous with in vitro measurements)

$\underline{\text { Individual }}$

Any human being.

\section{Internal Dose or Exposure}

That portion of the dose equivalent received from radiation sources inside the human body. 


\section{Isotope}

Atoms with the same number of protons but different numbers of neutrons are called isotopes of a specific element. We identify different isotopes by appending the total number of nucleons (the total number of proton plus neutrons in the nucleus of an atom) to the name of the element, e.g., cesium 137. Isotopes are usually written in an abbreviated form using the chemical symbol of the element. Two examples include ${ }^{137} \mathrm{Cs}$ for cesium- $137,{ }^{239} \mathrm{Pu}$ for plutonium-239, and ${ }^{40} \mathrm{~K}$ for potassium.

\section{Minimum Detectable Amount}

The smallest activity or mass of an analyte in a sample or person that can be detected with an acceptable level of uncertainty.

\section{Monitoring}

The measurement of radiation levels or individual doses and the use of the results to assess radiological hazards or potential and actual doses resulting from exposures to ionizing radiation.

\section{Quality Assurance}

All those planned and systematic actions necessary to provide adequate confidence that an analyses, measurement, or surveillance program will perform satisfactorily.

\section{Quality Control}

Those actions that control the attributes of analytical process, system, or facility according to predetermined quality requirements.

\section{$\underline{\text { Radiation Dose (or mrem) }}$}

A generic term to describe the amount of radiation a person receives. Dose is measured in units of thousands of a roentegen equivalent man (rem) (called the millirem). The millirem is normally abbreviated as mrem. Dose is a general term used to assist in the management of individual exposure to radiation.

The international scientific community has adopted the use of a different term for millirem called a millisievert $(\mathrm{mSv})$. One $\mathrm{mSv}$ is the same as $100 \mathrm{mrem}$.

\section{$\underline{\text { Radioactivity }}$}

A natural and spontaneous process by which unstable atoms of an element emit energy and/or particles from their nuclei and, thus, change (or decay) to atoms of a different element or a different state of the same element.

\section{Validation}

Defining the process of the method capability and determining whether it can be properly applied as intended.

\section{Whole-body}

For the purposes of external exposure includes the head, trunk, the arms above and including the elbow, and legs above and including the knee. 


\section{Appendix A: INDIVIDUAL MEASUREMENT DATA}

The following data tables provide full disclosure of all verified measurement data collected to 31 December 2001.

Table 1. Whole-body count data for Resettlement Workers on Rongelap Island (1999).

Table 2. Whole-body count data for Resettlement Workers on Rongelap Island (2000).

Table 3. Whole-body count data for Resettlement Workers on Rongelap Island (2001).

Table 4. Rongelap plutonium urinalysis data (1998-1999) from the University of Utah (Fission Track Analysis).

Table 5. Plutonium urinalysis data for resettlement workers on Rongelap Island (CAMS/LLNL, 1998-2001). 
Table 1. Whole-body count data for resettlement workers on Rongelap Island (1999).

\begin{tabular}{|c|c|c|c|c|c|c|c|c|c|c|c|c|c|}
\hline \multirow[b]{2}{*}{ ID\# } & \multirow[b]{2}{*}{$\begin{array}{r}\text { Age } \\
\text { Type }\end{array}$} & \multirow[b]{2}{*}{ Gender } & \multirow[b]{2}{*}{$\begin{array}{c}\text { Count } \\
\text { Date }\end{array}$} & \multicolumn{4}{|c|}{${ }^{40} K(\mathrm{kBq})^{a}$} & \multicolumn{4}{|c|}{${ }^{137} \mathrm{Cs}(\mathrm{kBq})^{\mathrm{a}}$} & \multirow[b]{2}{*}{ Code } & \multirow[b]{2}{*}{ Notes } \\
\hline & & & & Value & $\begin{array}{l}\text { Upper } \\
\text { Level }\end{array}$ & $\begin{array}{c}\text { Lower } \\
\text { Level }\end{array}$ & MDA & Value & $\begin{array}{l}\text { Upper } \\
\text { Level }\end{array}$ & $\begin{array}{c}\text { Lower } \\
\text { Level }\end{array}$ & MDA & & \\
\hline 05 & Adult & Male & 10/28/1999 & 5.8 & 6.1 & 5.5 & 0.7 & 0.19 & 0.21 & 0.18 & 0.084 & NaI_WBC & \\
\hline 07 & Adult & Male & 11/1/1999 & 3.5 & 3.7 & 3.3 & 0.8 & 0.069 & 0.082 & 0.055 & 0.094 & NaI_WBC & \\
\hline 07 & Adult & Male & $12 / 7 / 1999$ & 3.4 & 3.6 & 3.2 & 0.8 & 0.032 & 0.042 & 0.023 & 0.088 & NaI_WBC & \\
\hline 09 & Adult & Male & 10/27/1999 & 5.1 & 5.3 & 4.8 & 0.7 & 0.33 & 0.35 & 0.31 & 0.089 & NaI_WBC & \\
\hline 11 & Adult & Male & 11/8/1999 & 3.8 & 4.0 & 3.6 & 0.8 & 0.00 & 0.00 & 0.00 & 0.070 & NaI_WBC & \\
\hline 24 & Adult & Male & 10/27/1999 & 4.2 & 4.4 & 4.0 & 0.7 & 0.06 & 0.074 & 0.047 & 0.078 & NaI_WBC & \\
\hline 24 & Adult & Male & $11 / 9 / 1999$ & 4.4 & 4.6 & 4.1 & 0.8 & 0.039 & 0.052 & 0.027 & 0.096 & NaI_WBC & \\
\hline 25 & Adult & Male & $11 / 1 / 1999$ & 5.1 & 5.4 & 4.8 & 0.9 & 0.54 & 0.57 & 0.52 & 0.11 & NaI_WBC & \\
\hline 25 & Adult & Male & 11/11/1999 & 5.6 & 5.9 & 5.4 & 0.8 & 0.49 & 0.51 & 0.47 & 0.11 & NaI_WBC & \\
\hline 26 & Adult & Male & 10/27/1999 & 4.7 & 4.9 & 4.5 & 0.7 & 0.32 & 0.34 & 0.30 & 0.091 & NaI_WBC & \\
\hline 26 & Adult & Male & 11/15/1999 & 4.4 & 4.7 & 4.2 & 0.8 & 0.19 & 0.20 & 0.17 & 0.11 & NaI_WBC & \\
\hline 29 & Adult & Male & 10/28/1999 & 4.3 & 4.5 & 4.1 & 0.7 & 0.24 & 0.26 & 0.23 & 0.084 & NaI_WBC & \\
\hline 29 & Adult & Male & $12 / 4 / 1999$ & 3.1 & 3.3 & 2.9 & 0.9 & 0.18 & 0.20 & 0.17 & 0.11 & NaI_WBC & \\
\hline 30 & Adult & Male & $11 / 8 / 1999$ & 3.6 & 3.8 & 3.4 & 0.8 & 0.00 & 0.00 & 0.00 & 0.071 & NaI_WBC & \\
\hline 30 & Adult & Male & 11/19/1999 & 3.9 & 4.1 & 3.7 & 0.8 & 0.054 & 0.067 & 0.041 & 0.10 & NaI_WBC & \\
\hline 31 & Adult & Male & $10 / 28 / 1999$ & 4.3 & 4.6 & 4.1 & 0.7 & 0.10 & 0.12 & 0.087 & 0.081 & NaI_WBC & \\
\hline 31 & Adult & Male & $12 / 3 / 1999$ & 3.5 & 3.7 & 3.3 & 0.9 & 0.12 & 0.13 & 0.11 & 0.11 & NaI_WBC & \\
\hline 33 & Adult & Male & $10 / 28 / 1999$ & 4.7 & 5.0 & 4.5 & 0.7 & 0.74 & 0.77 & 0.71 & 0.088 & NaI_WBC & \\
\hline 33 & Adult & Male & $12 / 6 / 1999$ & 4.4 & 4.7 & 4.2 & 0.8 & 0.60 & 0.63 & 0.58 & 0.11 & NaI_WBC & \\
\hline 34 & Adult & Male & 10/28/1999 & 4.1 & 4.3 & 3.9 & 0.7 & 0.15 & 0.17 & 0.14 & 0.081 & NaI_WBC & \\
\hline 34 & Adult & Male & 11/12/1999 & 4.3 & 4.6 & 4.1 & 0.8 & 0.17 & 0.18 & 0.15 & 0.11 & NaI_WBC & \\
\hline 36 & Adult & Male & $11 / 8 / 1999$ & 4.7 & 4.9 & 4.4 & 0.8 & 0.00 & 0.00 & 0.00 & 0.066 & NaI_WBC & \\
\hline 37 & Adult & Male & $11 / 8 / 1999$ & 3.7 & 3.9 & 3.5 & 0.8 & 0.00 & 0.00 & 0.00 & 0.066 & NaI_WBC & \\
\hline 38 & Adult & Male & 11/1/1999 & 3.6 & 3.8 & 3.4 & 0.8 & 0.00 & 0.00 & 0.00 & 0.066 & NaI_WBC & \\
\hline 38 & Adult & Male & $12 / 6 / 1999$ & 3.6 & 3.8 & 3.4 & 0.8 & 0.00 & 0.00 & 0.00 & 0.066 & NaI_WBC & \\
\hline 52 & Adult & Male & 10/28/1999 & 4.4 & 4.6 & 4.1 & 0.7 & 0.23 & 0.25 & 0.21 & 0.085 & NaI_WBC & \\
\hline 52 & Adult & Male & 11/10/1999 & 4.0 & 4.2 & 3.8 & 0.9 & 0.16 & 0.17 & 0.14 & 0.098 & NaI_WBC & \\
\hline 53 & Adult & Male & $10 / 27 / 1999$ & 4.8 & 5.0 & 4.5 & 0.7 & 0.14 & 0.16 & 0.13 & 0.084 & NaI_WBC & \\
\hline 53 & Adult & Male & $12 / 3 / 1999$ & 3.0 & 3.2 & 2.8 & 0.9 & 0.094 & 0.11 & 0.082 & 0.11 & NaI_WBC & \\
\hline 54 & Adult & Male & 10/28/1999 & 4.2 & 4.4 & 4.0 & 0.7 & 0.26 & 0.28 & 0.24 & 0.086 & NaI_WBC & \\
\hline 54 & Adult & Male & $12 / 2 / 1999$ & 0.0 & 0.0 & 0.0 & 0.6 & 0.12 & 0.13 & 0.10 & 0.10 & NaI_WBC & Note A \\
\hline 55 & Adult & Male & 10/28/1999 & 4.0 & 4.2 & 3.8 & 0.7 & 0.25 & 0.26 & 0.23 & 0.086 & NaI_WBC & \\
\hline 55 & Adult & Male & 11/16/1999 & 3.8 & 4.0 & 3.6 & 0.9 & 0.17 & 0.18 & 0.15 & 0.11 & NaI_WBC & \\
\hline 56 & Adult & Male & 10/28/1999 & 4.5 & 4.8 & 4.3 & 0.7 & 0.32 & 0.34 & 0.30 & 0.086 & NaI_WBC & \\
\hline 56 & Adult & Male & $12 / 4 / 1999$ & 3.6 & 3.8 & 3.4 & 0.9 & 0.22 & 0.24 & 0.20 & 0.11 & NaI_WBC & \\
\hline 57 & Adult & Male & $10 / 28 / 1999$ & 4.8 & 5.0 & 4.5 & 0.7 & 0.073 & 0.087 & 0.059 & 0.080 & NaI_WBC & \\
\hline 57 & Adult & Male & $12 / 2 / 1999$ & 0.6 & 0.7 & 0.4 & 0.9 & 0.034 & 0.044 & 0.025 & 0.086 & NaI_WBC & Note A \\
\hline 58 & Adult & Male & 10/28/1999 & 4.0 & 4.2 & 3.8 & 0.7 & 0.20 & 0.21 & 0.18 & 0.084 & NaI_WBC & \\
\hline 58 & Adult & Male & $12 / 4 / 1999$ & 3.3 & 3.5 & 3.1 & 0.8 & 0.12 & 0.13 & 0.11 & 0.10 & NaI_WBC & \\
\hline 62 & Adult & Male & $11 / 8 / 1999$ & 4.8 & 5.0 & 4.5 & 0.8 & 0.043 & 0.057 & 0.030 & 0.11 & NaI_WBC & \\
\hline 62 & Adult & Male & $12 / 6 / 1999$ & 4.5 & 4.8 & 4.3 & 0.8 & 0.12 & 0.14 & 0.11 & 0.11 & NaI_WBC & \\
\hline 63 & Adult & Male & 11/17/1999 & 3.2 & 3.4 & 3.0 & 0.8 & 0.00 & 0.00 & 0.00 & 0.066 & NaI_WBC & \\
\hline 64 & Adult & Male & 11/19/1999 & 4.7 & 4.9 & 4.5 & 0.8 & 0.00 & 0.00 & 0.00 & 0.066 & NaI_WBC & \\
\hline 65 & Adult & Male & $12 / 2 / 1999$ & 0.0 & 0.0 & 0.0 & 0.5 & 0.00 & 0.00 & 0.00 & 0.061 & NaI_WBC & Note $A$ \\
\hline
\end{tabular}


Table 1. (Continued).

\begin{tabular}{|c|c|c|c|c|c|c|c|c|c|c|c|c|c|}
\hline \multirow[b]{2}{*}{ ID\# } & \multirow[b]{2}{*}{$\begin{array}{r}\text { Age } \\
\text { Type }\end{array}$} & \multirow[b]{2}{*}{ Gender } & \multirow[b]{2}{*}{$\begin{array}{c}\text { Count } \\
\text { Date }\end{array}$} & \multicolumn{4}{|c|}{${ }^{40} \mathrm{~K}(\mathrm{kBq})^{\mathrm{a}}$} & \multicolumn{4}{|c|}{${ }^{137} \mathrm{Cs}(\mathrm{kBq})^{\mathrm{a}}$} & \multirow[b]{2}{*}{ Code } & \multirow[b]{2}{*}{ Notes } \\
\hline & & & & Value & $\begin{array}{l}\text { Upper } \\
\text { Level }\end{array}$ & $\begin{array}{c}\text { Lower } \\
\text { Level }\end{array}$ & MDA & Value & $\begin{array}{r}\text { Upper } \\
\text { Level }\end{array}$ & $\begin{array}{c}\text { Lower } \\
\text { Level }\end{array}$ & MDA & & \\
\hline 66 & Adult & Male & $11 / 8 / 1999$ & 3.3 & 3.5 & 3.1 & 0.8 & 0.00 & 0.00 & 0.00 & 0.064 & NaI_WBC & \\
\hline 66 & Adult & Male & $12 / 7 / 1999$ & 3.6 & 3.8 & 3.4 & 0.8 & 0.00 & 0.00 & 0.00 & 0.064 & NaI_WBC & \\
\hline 68 & Adult & Male & 11/17/1999 & 3.6 & 3.8 & 3.4 & 0.8 & 0.00 & 0.00 & 0.00 & 0.066 & NaI_WBC & \\
\hline 69 & Adult & Male & $11 / 8 / 1999$ & 4.6 & 4.9 & 4.4 & 0.8 & 0.072 & 0.085 & 0.059 & 0.092 & NaI_WBC & \\
\hline 69 & Adult & Male & $12 / 3 / 1999$ & 3.2 & 3.4 & 3.0 & 0.9 & 0.18 & 0.19 & 0.16 & 0.11 & NaI_WBC & \\
\hline 70 & Adult & Male & 11/19/1999 & 4.0 & 4.2 & 3.7 & 0.9 & 0.00 & 0.00 & 0.00 & 0.065 & NaI_WBC & \\
\hline 73 & Adult & Male & $11 / 8 / 1999$ & 4.0 & 4.2 & 3.7 & 0.8 & 0.098 & 0.11 & 0.085 & 0.11 & NaI_WBC & \\
\hline 73 & Adult & Male & $12 / 4 / 1999$ & 3.1 & 3.3 & 2.9 & 0.9 & 0.14 & 0.16 & 0.13 & 0.11 & NaI_WBC & \\
\hline 76 & Adult & Male & 11/17/1999 & 4.3 & 4.6 & 4.1 & 0.8 & 0.23 & 0.25 & 0.21 & 0.11 & NaI_WBC & \\
\hline
\end{tabular}

a Upper and lower limits represent uncertainties in the measurements based on counting statistics $( \pm 1 \sigma)$.

Note A: Suspect potassium-40 $\left({ }^{40} \mathrm{~K}\right)$ result, but Q.C. for cesium-137 $\left({ }^{137} \mathrm{Cs}\right)$ was within the acceptable range. 
Table 2. Whole-body count data for resettlement workers on Rongelap Island (2000).

\begin{tabular}{|c|c|c|c|c|c|c|c|c|c|c|c|c|c|}
\hline \multirow[b]{2}{*}{ ID\# } & \multirow[b]{2}{*}{$\begin{array}{l}\text { Age } \\
\text { Type }\end{array}$} & \multirow[b]{2}{*}{ Gender } & \multirow[b]{2}{*}{$\begin{array}{l}\text { Count } \\
\text { Date }\end{array}$} & \multicolumn{4}{|c|}{${ }^{40} \mathrm{~K}(\mathrm{kBq})^{\mathrm{a}}$} & \multicolumn{4}{|c|}{${ }^{137} \mathrm{Cs}(\mathrm{kBq})^{\mathrm{a}}$} & \multirow[b]{2}{*}{ Code } & \multirow[b]{2}{*}{ Notes } \\
\hline & & & & Value & $\begin{array}{c}\text { Upper } \\
\text { Level }\end{array}$ & $\begin{array}{c}\text { Lower } \\
\text { Level }\end{array}$ & MDA & Value & $\begin{array}{l}\text { Upper } \\
\text { Level }\end{array}$ & $\begin{array}{c}\text { Lower } \\
\text { Level }\end{array}$ & MDA & & \\
\hline 05 & Adult & Male & $1 / 28 / 2000$ & 4.4 & 4.6 & 4.2 & 0.8 & 0.10 & 0.12 & 0.085 & 0.12 & NaI_WBC & \\
\hline 05 & Adult & Male & $3 / 10 / 2000$ & 4.4 & 4.6 & 4.1 & 0.8 & 0.00 & 0.00 & 0.00 & 0.073 & NaI_WBC & \\
\hline 05 & Adult & Male & $5 / 4 / 2000$ & 3.7 & 3.9 & 3.5 & 0.9 & 0.00 & 0.00 & 0.00 & 0.074 & NaI_WBC & \\
\hline 05 & Adult & Male & $11 / 9 / 2000$ & 6.5 & 6.8 & 6.3 & 1.1 & 0.00 & 0.00 & 0.00 & 0.065 & NaI_WBC & \\
\hline 07 & Adult & Male & $1 / 19 / 2000$ & 0.0 & 0.0 & 0.0 & 1.0 & 0.17 & 0.20 & 0.13 & 0.22 & NaI_WBC & Note A \\
\hline 07 & Adult & Male & $2 / 2 / 2000$ & 3.5 & 3.7 & 3.3 & 0.8 & 0.00 & 0.00 & 0.00 & 0.073 & NaI_WBC & \\
\hline 07 & Adult & Male & $3 / 3 / 2000$ & 3.5 & 3.7 & 3.3 & 0.8 & 0.00 & 0.00 & 0.00 & 0.071 & NaI_WBC & \\
\hline 07 & Adult & Male & $7 / 4 / 2000$ & 2.9 & 3.1 & 2.7 & 0.9 & 0.092 & 0.11 & 0.077 & 0.10 & NaI_WBC & \\
\hline 07 & Adult & Male & $11 / 2 / 2000$ & 3.9 & 4.1 & 3.7 & 1.0 & 0.00 & 0.00 & 0.00 & 0.069 & NaI_WBC & \\
\hline 07 & Adult & Male & $12 / 1 / 2000$ & 4.0 & 4.2 & 3.8 & 1.1 & 0.00 & 0.00 & 0.00 & 0.062 & NaI_WBC & \\
\hline 11 & Adult & Male & $1 / 21 / 2000$ & 0.0 & 0.0 & 0.0 & 1.0 & 0.28 & 0.31 & 0.24 & 0.22 & NaI_WBC & Note A \\
\hline 11 & Adult & Male & $2 / 17 / 2000$ & 3.6 & 3.8 & 3.4 & 0.8 & 0.12 & 0.14 & 0.11 & 0.10 & NaI_WBC & \\
\hline 11 & Adult & Male & $3 / 13 / 2000$ & 4.2 & 4.5 & 4.0 & 0.8 & 0.12 & 0.14 & 0.099 & 0.12 & NaI_WBC & \\
\hline 24 & Adult & Male & $1 / 17 / 2000$ & 1.2 & 2.4 & 0.0 & 1.4 & 0.13 & 0.16 & 0.099 & 0.20 & NaI_WBC & Note A. \\
\hline 24 & Adult & Male & $1 / 31 / 2000$ & 3.5 & 3.7 & 3.3 & 0.8 & 0.070 & 0.082 & 0.058 & 0.095 & NaI_WBC & \\
\hline 24 & Adult & Male & $3 / 2 / 2000$ & 4.4 & 4.6 & 4.2 & 0.8 & 0.051 & 0.063 & 0.039 & 0.095 & NaI_WBC & \\
\hline 25 & Adult & Male & $1 / 19 / 2000$ & 0.0 & 0.0 & 0.0 & 1.1 & 0.33 & 0.36 & 0.29 & 0.23 & NaI_WBC & Note A \\
\hline 25 & Adult & Male & $2 / 1 / 2000$ & 4.7 & 5.0 & 4.5 & 0.8 & 0.41 & 0.43 & 0.39 & 0.12 & NaI_WBC & \\
\hline 25 & Adult & Male & $3 / 3 / 2000$ & 4.8 & 5.1 & 4.6 & 0.8 & 0.37 & 0.39 & 0.35 & 0.12 & NaI_WBC & \\
\hline 26 & Adult & Male & $1 / 19 / 2000$ & 0.0 & 0.0 & 0.0 & 1.1 & 0.28 & 0.32 & 0.24 & 0.21 & NaI_WBC & Note A \\
\hline 26 & Adult & Male & $2 / 2 / 2000$ & 4.6 & 4.8 & 4.3 & 0.8 & 0.18 & 0.20 & 0.17 & 0.11 & NaI_WBC & \\
\hline 26 & Adult & Male & $3 / 10 / 2000$ & 4.3 & 4.6 & 4.1 & 0.8 & 0.11 & 0.13 & 0.10 & 0.11 & NaI_WBC & \\
\hline 26 & Adult & Male & $5 / 1 / 2000$ & 4.2 & 4.4 & 4.0 & 0.8 & 0.16 & 0.18 & 0.14 & 0.11 & NaI_WBC & \\
\hline 26 & Adult & Male & $7 / 3 / 2000$ & 3.9 & 4.1 & 3.7 & 0.8 & 0.28 & 0.30 & 0.26 & 0.11 & NaI_WBC & \\
\hline 26 & Adult & Male & $11 / 3 / 2000$ & 4.9 & 5.1 & 4.6 & 1.0 & 0.28 & 0.30 & 0.26 & 0.11 & NaI_WBC & \\
\hline 29 & Adult & Male & $1 / 31 / 2000$ & 3.5 & 3.7 & 3.3 & 0.8 & 0.16 & 0.18 & 0.15 & 0.10 & NaI_WBC & \\
\hline 29 & Adult & Male & $3 / 8 / 2000$ & 4.2 & 4.4 & 4.0 & 0.8 & 0.081 & 0.094 & 0.068 & 0.11 & NaI_WBC & \\
\hline 29 & Adult & Male & $4 / 7 / 2000$ & 2.7 & 2.9 & 2.5 & 0.9 & 0.088 & 0.11 & 0.069 & 0.12 & NaI_WBC & \\
\hline 29 & Adult & Male & $5 / 9 / 2000$ & 4.0 & 4.2 & 3.8 & 0.9 & 0.11 & 0.12 & 0.095 & 0.097 & NaI_WBC & \\
\hline 29 & Adult & Male & $7 / 3 / 2000$ & 3.8 & 4.0 & 3.6 & 0.8 & 0.17 & 0.18 & 0.15 & 0.11 & NaI_WBC & \\
\hline 29 & Adult & Male & $11 / 3 / 2000$ & 4.6 & 4.9 & 4.4 & 1.0 & 0.24 & 0.26 & 0.22 & 0.10 & NaI_WBC & \\
\hline 29 & Adult & Male & $12 / 1 / 2000$ & 4.9 & 5.2 & 4.7 & 1.0 & 0.20 & 0.22 & 0.19 & 0.10 & NaI_WBC & \\
\hline 30 & Adult & Male & $1 / 17 / 2000$ & 1.2 & 2.4 & 0.0 & 1.4 & 0.24 & 0.28 & 0.21 & 0.22 & NaI_WBC & Note A \\
\hline 30 & Adult & Male & $2 / 2 / 2000$ & 3.9 & 4.1 & 3.7 & 0.8 & 0.24 & 0.25 & 0.22 & 0.12 & NaI_WBC & \\
\hline 30 & Adult & Male & $3 / 2 / 2000$ & 4.0 & 4.2 & 3.8 & 0.8 & 0.25 & 0.26 & 0.23 & 0.12 & NaI_WBC & \\
\hline 30 & Adult & Male & $5 / 10 / 2000$ & 4.2 & 4.4 & 3.9 & 0.8 & 0.20 & 0.22 & 0.19 & 0.098 & NaI_WBC & \\
\hline 30 & Adult & Male & $11 / 7 / 2000$ & 5.1 & 5.4 & 4.9 & 1.1 & 0.22 & 0.23 & 0.20 & 0.11 & NaI_WBC & \\
\hline 31 & Adult & Male & $1 / 20 / 2000$ & 0.0 & 0.0 & 0.0 & 1.1 & 0.20 & 0.24 & 0.17 & 0.22 & NaI_WBC & Note A \\
\hline 31 & Adult & Male & $2 / 4 / 2000$ & 4.6 & 4.8 & 4.3 & 0.8 & 0.067 & 0.080 & 0.054 & 0.10 & NaI_WBC & \\
\hline 33 & Adult & Male & $1 / 26 / 2000$ & 4.0 & 4.2 & 3.8 & 0.8 & 0.56 & 0.59 & 0.54 & 0.12 & NaI_WBC & \\
\hline 33 & Adult & Male & $3 / 9 / 2000$ & 4.1 & 4.3 & 3.8 & 0.8 & 0.56 & 0.59 & 0.54 & 0.12 & NaI_WBC & \\
\hline 33 & Adult & Male & $5 / 3 / 2000$ & 4.4 & 4.6 & 4.2 & 0.9 & 0.59 & 0.62 & 0.56 & 0.12 & NaI_WBC & \\
\hline 33 & Adult & Male & $11 / 2 / 2000$ & 5.0 & 5.2 & 4.7 & 1.0 & 0.76 & 0.80 & 0.72 & 0.12 & NaI_WBC & \\
\hline 34 & Adult & Male & $1 / 18 / 2000$ & 0.0 & 0.0 & 0.0 & 1.1 & 0.095 & 0.12 & 0.067 & 0.20 & NaI_WBC & Note A \\
\hline
\end{tabular}


Table 2. (Continued).

\begin{tabular}{|c|c|c|c|c|c|c|c|c|c|c|c|c|c|}
\hline \multirow[b]{2}{*}{ ID\# } & \multirow[b]{2}{*}{$\begin{array}{c}\text { Age } \\
\text { Type }\end{array}$} & \multirow[b]{2}{*}{ Gender } & \multirow[b]{2}{*}{$\begin{array}{l}\text { Count } \\
\text { Date }\end{array}$} & \multicolumn{4}{|c|}{${ }^{40} K(\mathrm{kBq})^{\mathrm{a}}$} & \multicolumn{4}{|c|}{${ }^{137} \mathrm{Cs}(\mathrm{kBq})^{\mathrm{a}}$} & \multirow[b]{2}{*}{ Code } & \multirow[b]{2}{*}{ Notes } \\
\hline & & & & Value & $\begin{array}{r}\text { Upper } \\
\text { Level }\end{array}$ & $\begin{array}{c}\text { Lower } \\
\text { Level }\end{array}$ & MDA & Value & $\begin{array}{c}\text { Upper } \\
\text { Level }\end{array}$ & $\begin{array}{c}\text { Lower } \\
\text { Level }\end{array}$ & MDA & & \\
\hline 34 & Adult & Male & $2 / 1 / 2000$ & 3.9 & 4.2 & 3.7 & 0.8 & 0.10 & 0.12 & 0.089 & 0.10 & NaI_WBC & \\
\hline 34 & Adult & Male & $3 / 2 / 2000$ & 4.3 & 4.5 & 4.1 & 0.8 & 0.079 & 0.092 & 0.066 & 0.11 & NaI_WBC & \\
\hline 34 & Adult & Male & $5 / 3 / 2000$ & 3.8 & 4.0 & 3.6 & 0.9 & 0.00 & 0.00 & 0.00 & 0.076 & NaI_WBC & \\
\hline 34 & Adult & Male & $7 / 3 / 2000$ & 3.6 & 3.8 & 3.4 & 0.9 & 0.11 & 0.12 & 0.096 & 0.10 & NaI_WBC & \\
\hline 35 & Adult & Male & $5 / 1 / 2000$ & 4.5 & 4.7 & 4.3 & 0.8 & 0.16 & 0.17 & 0.14 & 0.10 & NaI_WBC & \\
\hline 38 & Adult & Male & $1 / 28 / 2000$ & 3.7 & 3.9 & 3.5 & 0.8 & 0.00 & 0.00 & 0.00 & 0.072 & NaI_WBC & \\
\hline 38 & Adult & Male & $3 / 8 / 2000$ & 3.6 & 3.8 & 3.4 & 0.8 & 0.00 & 0.00 & 0.00 & 0.070 & NaI_WBC & \\
\hline 38 & Adult & Male & $4 / 22 / 2000$ & 3.6 & 3.8 & 3.4 & 0.8 & 0.00 & 0.00 & 0.00 & 0.071 & NaI_WBC & \\
\hline 38 & Adult & Male & $11 / 5 / 2000$ & 4.7 & 4.9 & 4.5 & 1.1 & 0.00 & 0.00 & 0.00 & 0.062 & NaI_WBC & \\
\hline 38 & Adult & Male & $12 / 3 / 2000$ & 4.8 & 5.0 & 4.5 & 1.0 & 0.00 & 0.00 & 0.00 & 0.060 & NaI_WBC & \\
\hline 52 & Adult & Male & $1 / 18 / 2000$ & 0.0 & 0.0 & 0.0 & 1.0 & 0.12 & 0.15 & 0.089 & 0.21 & NaI_WBC & Note A \\
\hline 52 & Adult & Male & $2 / 1 / 2000$ & 4.0 & 4.3 & 3.8 & 0.8 & 0.25 & 0.27 & 0.24 & 0.11 & NaI_WBC & \\
\hline 52 & Adult & Male & $3 / 2 / 2000$ & 4.3 & 4.5 & 4.1 & 0.8 & 0.24 & 0.26 & 0.23 & 0.12 & NaI_WBC & \\
\hline 52 & Adult & Male & $5 / 8 / 2000$ & 4.0 & 4.2 & 3.8 & 0.9 & 0.26 & 0.28 & 0.24 & 0.11 & NaI_WBC & \\
\hline 52 & Adult & Male & $7 / 3 / 2000$ & 4.2 & 4.4 & 4.0 & 0.8 & 0.33 & 0.34 & 0.31 & 0.11 & NaI_WBC & \\
\hline 53 & Adult & Male & $1 / 20 / 2000$ & 0.0 & 0.0 & 0.0 & 1.1 & 0.00 & 0.00 & 0.00 & 0.15 & NaI_WBC & Note A \\
\hline 53 & Adult & Male & $2 / 4 / 2000$ & 4.2 & 4.4 & 3.9 & 0.8 & 0.10 & 0.12 & 0.092 & 0.095 & NaI_WBC & \\
\hline 53 & Adult & Male & $3 / 4 / 2000$ & 4.5 & 4.8 & 4.3 & 0.8 & 0.093 & 0.11 & 0.080 & 0.098 & NaI_WBC & \\
\hline 54 & Adult & Male & $1 / 18 / 2000$ & 0.0 & 0.0 & 0.0 & 1.0 & 0.20 & 0.24 & 0.17 & 0.22 & NaI_WBC & Note A \\
\hline 54 & Adult & Male & $1 / 31 / 2000$ & 4.0 & 4.2 & 3.7 & 0.8 & 0.15 & 0.17 & 0.14 & 0.11 & NaI_WBC & \\
\hline 54 & Adult & Male & $2 / 3 / 2000$ & 4.5 & 4.7 & 4.2 & 0.8 & 0.11 & 0.12 & 0.094 & 0.10 & NaI_WBC & \\
\hline 54 & Adult & Male & $5 / 1 / 2000$ & 4.4 & 4.6 & 4.2 & 0.9 & 0.051 & 0.065 & 0.037 & 0.10 & NaI_WBC & \\
\hline 54 & Adult & Male & $11 / 2 / 2000$ & 4.8 & 5.0 & 4.5 & 1.0 & 0.28 & 0.30 & 0.26 & 0.10 & NaI_WBC & \\
\hline 54 & Adult & Male & $11 / 30 / 2000$ & 4.9 & 5.1 & 4.7 & 1.1 & 0.26 & 0.28 & 0.25 & 0.10 & NaI_WBC & \\
\hline 55 & Adult & Male & $1 / 17 / 2000$ & 1.4 & 2.8 & 0.0 & 1.5 & 0.19 & 0.22 & 0.16 & 0.21 & NaI_WBC & Note A \\
\hline 55 & Adult & Male & $2 / 3 / 2000$ & 4.4 & 4.6 & 4.2 & 0.8 & 0.14 & 0.15 & 0.12 & 0.096 & NaI_WBC & \\
\hline 57 & Adult & Male & $1 / 20 / 2000$ & 0.0 & 0.0 & 0.0 & 1.1 & 0.00 & 0.00 & 0.00 & 0.15 & NaI_WBC & Note A \\
\hline 57 & Adult & Male & $2 / 3 / 2000$ & 4.7 & 4.9 & 4.4 & 0.8 & 0.050 & 0.062 & 0.038 & 0.11 & NaI_WBC & \\
\hline 57 & Adult & Male & $3 / 3 / 2000$ & 4.5 & 4.7 & 4.3 & 0.8 & 0.044 & 0.056 & 0.031 & 0.097 & NaI_WBC & \\
\hline 57 & Adult & Male & $5 / 5 / 2000$ & 4.0 & 4.2 & 3.8 & 0.9 & 0.00 & 0.00 & 0.00 & 0.074 & NaI_WBC & \\
\hline 57 & Adult & Male & $11 / 2 / 2000$ & 5.3 & 5.6 & 5.1 & 1.0 & 0.044 & 0.057 & 0.030 & 0.11 & NaI_WBC & \\
\hline 62 & Adult & Male & $1 / 24 / 2000$ & 0.0 & 0.0 & 0.0 & 1.1 & 0.18 & 0.22 & 0.15 & 0.23 & NaI_WBC & Note A \\
\hline 62 & Adult & Male & $2 / 3 / 2000$ & 4.7 & 4.9 & 4.4 & 0.8 & 0.091 & 0.10 & 0.078 & 0.10 & NaI_WBC & \\
\hline 62 & Adult & Male & $3 / 13 / 2000$ & 5.2 & 5.4 & 4.9 & 0.8 & 0.068 & 0.086 & 0.049 & 0.12 & NaI_WBC & \\
\hline 62 & Adult & Male & $4 / 11 / 2000$ & 5.1 & 5.3 & 4.8 & 0.8 & 0.11 & 0.13 & 0.10 & 0.098 & NaI_WBC & \\
\hline 62 & Adult & Male & $5 / 9 / 2000$ & 4.8 & 5.1 & 4.6 & 0.9 & 0.16 & 0.17 & 0.14 & 0.10 & NaI_WBC & \\
\hline 62 & Adult & Male & $11 / 7 / 2000$ & 5.9 & 6.2 & 5.7 & 1.1 & 0.087 & 0.10 & 0.073 & 0.096 & NaI_WBC & \\
\hline 65 & Adult & Male & $2 / 17 / 2000$ & 3.8 & 4.0 & 3.6 & 0.8 & 0.00 & 0.00 & 0.00 & 0.072 & NaI_WBC & \\
\hline 65 & Adult & Male & $3 / 13 / 2000$ & 4.2 & 4.4 & 4.0 & 0.8 & 0.00 & 0.00 & 0.00 & 0.072 & NaI_WBC & \\
\hline 65 & Adult & Male & $4 / 7 / 2000$ & 1.6 & 1.8 & 1.4 & 0.9 & 0.00 & 0.00 & 0.00 & 0.073 & NaI_WBC & Note A \\
\hline 65 & Adult & Male & $5 / 3 / 2000$ & 4.0 & 4.2 & 3.8 & 0.9 & 0.00 & 0.00 & 0.00 & 0.073 & NaI_WBC & \\
\hline 65 & Adult & Male & $11 / 2 / 2000$ & 4.2 & 4.4 & 4.0 & 1.0 & 0.33 & 0.35 & 0.31 & 0.11 & NaI_WBC & \\
\hline 65 & Adult & Male & $12 / 1 / 2000$ & 4.8 & 5.0 & 4.6 & 1.1 & 0.30 & 0.32 & 0.28 & 0.10 & NaI_WBC & \\
\hline 66 & Adult & Male & $1 / 27 / 2000$ & 3.3 & 3.5 & 3.1 & 0.9 & 0.00 & 0.00 & 0.00 & 0.070 & NaI_WBC & \\
\hline
\end{tabular}


Table 2. (Continued).

\begin{tabular}{|c|c|c|c|c|c|c|c|c|c|c|c|c|c|}
\hline \multirow[b]{2}{*}{ ID\# } & \multirow[b]{2}{*}{$\begin{array}{l}\text { Age } \\
\text { Type }\end{array}$} & \multirow[b]{2}{*}{ Gender } & \multirow[b]{2}{*}{$\begin{array}{l}\text { Count } \\
\text { Date }\end{array}$} & \multicolumn{4}{|c|}{${ }^{40} \mathrm{~K}(\mathrm{kBq})^{\mathrm{a}}$} & \multicolumn{4}{|c|}{${ }^{137} \mathrm{Cs}(\mathrm{kBq})^{\mathrm{a}}$} & \multirow[b]{2}{*}{ Code } & \multirow[b]{2}{*}{ Notes } \\
\hline & & & & Value & $\begin{array}{l}\text { Upper } \\
\text { Level }\end{array}$ & $\begin{array}{c}\text { Lower } \\
\text { Level }\end{array}$ & MDA & Value & $\begin{array}{c}\text { Upper } \\
\text { Level }\end{array}$ & $\begin{array}{l}\text { Lower } \\
\text { Level }\end{array}$ & MDA & & \\
\hline 66 & Adult & Male & $4 / 22 / 2000$ & 3.5 & 3.7 & 3.3 & 0.8 & 0.00 & 0.00 & 0.00 & 0.069 & NaI_WBC & \\
\hline 69 & Adult & Male & $1 / 31 / 2000$ & 3.9 & 4.2 & 3.7 & 0.8 & 0.13 & 0.14 & 0.11 & 0.10 & NaI_WBC & \\
\hline 69 & Adult & Male & $3 / 6 / 2000$ & 4.5 & 4.7 & 4.3 & 0.8 & 0.19 & 0.20 & 0.17 & 0.12 & NaI_WBC & \\
\hline 69 & Adult & Male & $4 / 12 / 2000$ & 4.2 & 4.4 & 4.0 & 0.9 & 0.15 & 0.16 & 0.13 & 0.097 & NaI_WBC & \\
\hline 69 & Adult & Male & $5 / 10 / 2000$ & 4.2 & 4.4 & 4.0 & 0.8 & 0.14 & 0.15 & 0.12 & 0.098 & NaI_WBC & \\
\hline 69 & Adult & Male & $11 / 6 / 2000$ & 5.4 & 5.7 & 5.2 & 1.1 & 0.24 & 0.26 & 0.23 & 0.10 & NaI_WBC & \\
\hline 69 & Adult & Male & $12 / 1 / 2000$ & 4.7 & 4.9 & 4.5 & 1.1 & 0.22 & 0.24 & 0.21 & 0.10 & NaI_WBC & \\
\hline 73 & Adult & Male & $2 / 2 / 2000$ & 3.5 & 3.7 & 3.3 & 0.8 & 0.10 & 0.11 & 0.088 & 0.096 & NaI_WBC & \\
\hline 73 & Adult & Male & $3 / 8 / 2000$ & 3.8 & 4.1 & 3.6 & 0.8 & 0.088 & 0.10 & 0.075 & 0.10 & NaI_WBC & \\
\hline 73 & Adult & Male & $4 / 10 / 2000$ & 3.9 & 4.1 & 3.7 & 0.8 & 0.15 & 0.17 & 0.14 & 0.095 & NaI_WBC & \\
\hline 73 & Adult & Male & $11 / 12 / 2000$ & 4.9 & 5.1 & 4.6 & 1.1 & 0.18 & 0.20 & 0.17 & 0.10 & NaI_WBC & \\
\hline 74 & Adult & Male & $1 / 28 / 2000$ & 3.9 & 4.1 & 3.7 & 0.8 & 0.00 & 0.00 & 0.00 & 0.071 & NaI_WBC & \\
\hline 74 & Adult & Male & $3 / 6 / 2000$ & 3.9 & 4.1 & 3.7 & 0.8 & 0.00 & 0.00 & 0.00 & 0.073 & NaI_WBC & \\
\hline 74 & Adult & Male & $4 / 11 / 2000$ & 4.1 & 4.3 & 3.9 & 0.8 & 0.095 & 0.11 & 0.081 & 0.097 & NaI_WBC & \\
\hline 74 & Adult & Male & $5 / 9 / 2000$ & 3.8 & 4.0 & 3.6 & 0.8 & 0.086 & 0.099 & 0.072 & 0.096 & NaI_WBC & \\
\hline 75 & Adult & Male & $1 / 27 / 2000$ & 5.4 & 5.6 & 5.1 & 0.9 & 0.00 & 0.00 & 0.00 & 0.071 & NaI_WBC & \\
\hline 75 & Adult & Male & $3 / 6 / 2000$ & 5.5 & 5.7 & 5.2 & 0.8 & 0.00 & 0.00 & 0.00 & 0.073 & NaI_WBC & \\
\hline 75 & Adult & Male & $4 / 10 / 2000$ & 5.2 & 5.5 & 5.0 & 0.9 & 0.063 & 0.077 & 0.050 & 0.098 & NaI_WBC & \\
\hline 75 & Adult & Male & $5 / 9 / 2000$ & 5.1 & 5.3 & 4.9 & 0.9 & 0.064 & 0.077 & 0.051 & 0.098 & NaI_WBC & \\
\hline 76 & Adult & Male & $1 / 27 / 2000$ & 4.5 & 4.7 & 4.3 & 0.8 & 0.21 & 0.23 & 0.20 & 0.11 & NaI_WBC & \\
\hline 76 & Adult & Male & $3 / 4 / 2000$ & 4.5 & 4.7 & 4.2 & 0.8 & 0.17 & 0.18 & 0.15 & 0.12 & NaI_WBC & \\
\hline 76 & Adult & Male & $5 / 2 / 2000$ & 4.2 & 4.4 & 4.0 & 0.8 & 0.12 & 0.13 & 0.10 & 0.10 & NaI_WBC & \\
\hline 76 & Adult & Male & $7 / 4 / 2000$ & 4.0 & 4.2 & 3.8 & 0.9 & 0.25 & 0.26 & 0.23 & 0.10 & NaI_WBC & \\
\hline 76 & Adult & Male & $11 / 2 / 2000$ & 4.8 & 5.1 & 4.6 & 1.0 & 0.24 & 0.26 & 0.22 & 0.11 & NaI_WBC & \\
\hline 76 & Adult & Male & $11 / 30 / 2000$ & 4.8 & 5.0 & 4.6 & 1.1 & 0.26 & 0.27 & 0.24 & 0.10 & NaI_WBC & \\
\hline 78 & Adult & Male & $1 / 21 / 2000$ & 0.0 & 0.0 & 0.0 & 1.0 & 0.12 & 0.16 & 0.090 & 0.22 & NaI_WBC & Note A \\
\hline 78 & Adult & Male & $2 / 1 / 2000$ & 3.6 & 3.8 & 3.4 & 0.8 & 0.00 & 0.00 & 0.00 & 0.072 & NaI_WBC & \\
\hline 78 & Adult & Male & $3 / 4 / 2000$ & 4.2 & 4.4 & 4.0 & 0.8 & 0.00 & 0.00 & 0.00 & 0.074 & NaI_WBC & \\
\hline 78 & Adult & Male & $5 / 3 / 2000$ & 3.9 & 4.1 & 3.7 & 0.9 & 0.00 & 0.00 & 0.00 & 0.075 & NaI_WBC & \\
\hline 78 & Adult & Male & $7 / 4 / 2000$ & 3.4 & 3.6 & 3.2 & 0.9 & 0.16 & 0.18 & 0.15 & 0.10 & NaI_WBC & \\
\hline 79 & Adult & Male & $1 / 21 / 2000$ & 0.0 & 0.0 & 0.0 & 1.0 & 0.13 & 0.16 & 0.098 & 0.22 & NaI_WBC & Note A \\
\hline 79 & Adult & Male & $2 / 4 / 2000$ & 4.4 & 4.6 & 4.2 & 0.8 & 0.070 & 0.083 & 0.057 & 0.095 & NaI_WBC & \\
\hline 79 & Adult & Male & $3 / 6 / 2000$ & 4.6 & 4.8 & 4.3 & 0.8 & 0.060 & 0.072 & 0.047 & 0.099 & NaI_WBC & \\
\hline 79 & Adult & Male & $4 / 8 / 2000$ & 4.2 & 4.5 & 4.0 & 0.8 & 0.12 & 0.13 & 0.11 & 0.091 & NaI_WBC & \\
\hline 79 & Adult & Male & $5 / 5 / 2000$ & 4.6 & 4.8 & 4.4 & 0.9 & 0.065 & 0.079 & 0.051 & 0.10 & NaI_WBC & \\
\hline 80 & Adult & Male & $1 / 22 / 2000$ & 0.0 & 0.0 & 0.0 & 1.0 & 0.00 & 0.00 & 0.00 & 0.15 & NaI_WBC & Note A \\
\hline 80 & Adult & Male & $2 / 10 / 2000$ & 3.3 & 3.5 & 3.2 & 0.8 & 0.00 & 0.00 & 0.00 & 0.071 & NaI_WBC & \\
\hline 80 & Adult & Male & $3 / 9 / 2000$ & 3.8 & 4.0 & 3.6 & 0.8 & 0.00 & 0.00 & 0.00 & 0.072 & NaI_WBC & \\
\hline 81 & Adult & Male & $1 / 22 / 2000$ & 0.0 & 0.0 & 0.0 & 1.0 & 0.00 & 0.00 & 0.00 & 0.15 & NaI_WBC & Note A \\
\hline 81 & Adult & Male & $4 / 22 / 2000$ & 3.4 & 3.6 & 3.2 & 0.8 & 0.00 & 0.00 & 0.00 & 0.071 & NaI_WBC & \\
\hline 84 & Adult & Male & $2 / 4 / 2000$ & 4.7 & 4.9 & 4.4 & 0.8 & 0.00 & 0.00 & 0.00 & 0.071 & NaI_WBC & \\
\hline 84 & Adult & Male & $3 / 13 / 2000$ & 4.8 & 5.0 & 4.6 & 0.8 & 0.00 & 0.00 & 0.00 & 0.076 & NaI_WBC & \\
\hline 85 & Adult & Male & $2 / 23 / 2000$ & 3.9 & 4.1 & 3.7 & 0.8 & 0.00 & 0.00 & 0.00 & 0.070 & NaI_WBC & \\
\hline 85 & Adult & Male & $4 / 10 / 2000$ & 4.6 & 4.8 & 4.3 & 0.8 & 0.052 & 0.066 & 0.037 & 0.11 & NaI_WBC & \\
\hline
\end{tabular}


Table 2. (Continued).

\begin{tabular}{|c|c|c|c|c|c|c|c|c|c|c|c|c|c|}
\hline \multirow[b]{2}{*}{ ID\# } & \multirow[b]{2}{*}{$\begin{array}{l}\text { Age } \\
\text { Type }\end{array}$} & \multirow[b]{2}{*}{ Gender } & \multirow[b]{2}{*}{$\begin{array}{l}\text { Count } \\
\text { Date }\end{array}$} & \multicolumn{4}{|c|}{${ }^{40} \mathrm{~K}(\mathrm{kBq})^{\mathrm{a}}$} & \multicolumn{4}{|c|}{${ }^{137} \mathrm{Cs}(\mathrm{kBq})^{\mathrm{a}}$} & \multirow[b]{2}{*}{ Code } & \multirow[b]{2}{*}{ Notes } \\
\hline & & & & Value & $\begin{array}{l}\text { Upper } \\
\text { Level }\end{array}$ & $\begin{array}{c}\text { Lower } \\
\text { Level }\end{array}$ & MDA & Value & $\begin{array}{c}\text { Upper } \\
\text { Level }\end{array}$ & $\begin{array}{c}\text { Lower } \\
\text { Level }\end{array}$ & MDA & & \\
\hline 86 & Adult & Male & $2 / 23 / 2000$ & 3.9 & 4.1 & 3.7 & 0.8 & 0.00 & 0.00 & 0.00 & 0.070 & NaI_WBC & \\
\hline 86 & Adult & Male & $5 / 5 / 2000$ & 4.2 & 4.4 & 4.0 & 0.9 & 0.093 & 0.11 & 0.078 & 0.099 & NaI_WBC & \\
\hline 86 & Adult & Male & $11 / 5 / 2000$ & 5.6 & 5.8 & 5.3 & 1.1 & 0.12 & 0.14 & 0.11 & 0.11 & NaI_WBC & \\
\hline 86 & Adult & Male & $12 / 4 / 2000$ & 6.0 & 6.2 & 5.7 & 1.0 & 0.14 & 0.16 & 0.13 & 0.098 & NaI_WBC & \\
\hline 89 & Adult & Male & $4 / 22 / 2000$ & 4.0 & 4.2 & 3.8 & 0.8 & 0.00 & 0.00 & 0.00 & 0.069 & NaI_WBC & \\
\hline 95 & Adult & Male & $4 / 26 / 2000$ & 3.6 & 3.8 & 3.4 & 0.8 & 0.00 & 0.00 & 0.00 & 0.071 & NaI_WBC & \\
\hline 98 & Adult & Male & $5 / 1 / 2000$ & 4.5 & 4.7 & 4.3 & 0.9 & 0.00 & 0.00 & 0.00 & 0.073 & NaI_WBC & \\
\hline 98 & Adult & Male & $11 / 6 / 2000$ & 5.9 & 6.2 & 5.7 & 1.1 & 0.052 & 0.065 & 0.040 & 0.098 & NaI_WBC & \\
\hline 101 & Adult & Male & $4 / 26 / 2000$ & 4.6 & 4.8 & 4.3 & 0.9 & 0.00 & 0.00 & 0.00 & 0.070 & NaI_WBC & \\
\hline 120 & Adult & Male & $11 / 5 / 2000$ & 5.8 & 6.1 & 5.6 & 1.1 & 0.00 & 0.00 & 0.00 & 0.063 & NaI_WBC & \\
\hline 120 & Adult & Male & $12 / 3 / 2000$ & 5.6 & 5.9 & 5.4 & 0.9 & 0.025 & 0.031 & 0.019 & 0.044 & NaI_WBC & \\
\hline 121 & Adult & Male & $11 / 7 / 2000$ & 5.1 & 5.3 & 4.8 & 1.1 & 0.035 & 0.048 & 0.023 & 0.087 & NaI_WBC & \\
\hline 121 & Adult & Male & $12 / 4 / 2000$ & 4.6 & 4.9 & 4.4 & 1.1 & 0.051 & 0.060 & 0.041 & 0.10 & NaI_WBC & \\
\hline 123 & Adult & Male & $11 / 12 / 2000$ & 6.0 & 6.3 & 5.7 & 1.1 & 0.094 & 0.11 & 0.082 & 0.097 & NaI_WBC & \\
\hline 124 & Adult & Male & $11 / 7 / 2000$ & 5.5 & 5.8 & 5.3 & 1.1 & 0.00 & 0.00 & 0.00 & 0.064 & NaI_WBC & \\
\hline 125 & Adult & Male & $11 / 8 / 2000$ & 5.9 & 6.2 & 5.7 & 1.0 & 0.00 & 0.00 & 0.00 & 0.062 & NaI_WBC & \\
\hline 126 & Adult & Male & $11 / 5 / 2000$ & 6.3 & 6.6 & 6.0 & 1.1 & 0.00 & 0.00 & 0.00 & 0.065 & NaI_WBC & \\
\hline 127 & Adult & Male & $12 / 1 / 2000$ & 4.6 & 4.8 & 4.4 & 1.1 & 0.00 & 0.00 & 0.00 & 0.061 & NaI_WBC & \\
\hline 128 & Adult & Male & $11 / 30 / 2000$ & 5.5 & 5.7 & 5.3 & 1.0 & 0.00 & 0.00 & 0.00 & 0.061 & NaI_WBC & \\
\hline 129 & Adult & Male & $11 / 5 / 2000$ & 5.9 & 6.2 & 5.7 & 1.1 & 0.00 & 0.00 & 0.00 & 0.064 & NaI_WBC & \\
\hline 131 & Adult & Male & $11 / 5 / 2000$ & 6.3 & 6.6 & 6.0 & 1.1 & 0.00 & 0.00 & 0.00 & 0.062 & NaI_WBC & \\
\hline 132 & Adult & Male & $11 / 6 / 2000$ & 6.4 & 6.7 & 6.1 & 1.1 & 0.24 & 0.26 & 0.23 & 0.11 & NaI_WBC & \\
\hline 132 & Adult & Male & $12 / 4 / 2000$ & 6.2 & 6.5 & 5.9 & 1.1 & 0.16 & 0.17 & 0.15 & 0.089 & NaI_WBC & \\
\hline 136 & Adult & Male & $11 / 7 / 2000$ & 5.5 & 5.8 & 5.3 & 1.1 & 0.51 & 0.53 & 0.49 & 0.11 & NaI_WBC & \\
\hline 137 & Adult & Male & $11 / 6 / 2000$ & 6.0 & 6.2 & 5.7 & 1.1 & 0.26 & 0.28 & 0.25 & 0.11 & NaI_WBC & \\
\hline 137 & Adult & Male & $12 / 1 / 2000$ & 5.4 & 5.6 & 5.1 & 1.1 & 0.27 & 0.28 & 0.25 & 0.10 & NaI_WBC & \\
\hline
\end{tabular}

a Upper and lower limits represent uncertainties in the measurements based on counting statistics $( \pm 1 \sigma)$.

Note A: Suspect potassium-40 $\left({ }^{40} \mathrm{~K}\right)$ result, but Q.C. for cesium-137 $\left({ }^{137} \mathrm{Cs}\right)$ was within the acceptable range. 
Table 3. Whole-body count data for resettlement workers on Rongelap Island (2001).

\begin{tabular}{|c|c|c|c|c|c|c|c|c|c|c|c|c|}
\hline \multirow[b]{2}{*}{ ID\# } & \multirow[b]{2}{*}{$\begin{array}{l}\text { Age } \\
\text { Type }\end{array}$} & \multirow[b]{2}{*}{ Gender } & \multirow[b]{2}{*}{$\begin{array}{l}\text { Count } \\
\text { Date }\end{array}$} & \multicolumn{4}{|c|}{${ }^{40} \mathrm{~K}(\mathrm{kBq})^{\mathrm{a}}$} & \multicolumn{4}{|c|}{${ }^{137} \mathrm{Cs}(\mathrm{kBq})^{\mathrm{a}}$} & \multirow[b]{2}{*}{ Code } \\
\hline & & & & Value & $\begin{array}{l}\text { Upper } \\
\text { Level }\end{array}$ & $\begin{array}{l}\text { Lower } \\
\text { Level }\end{array}$ & MDA & Value & $\begin{array}{l}\text { Upper } \\
\text { Level }\end{array}$ & $\begin{array}{c}\text { Lower } \\
\text { Level }\end{array}$ & MDA & \\
\hline 05 & Adult & Male & $3 / 29 / 2001$ & 4.7 & 4.9 & 4.5 & 1.0 & 0.00 & 0.00 & 0.00 & 0.061 & NaI_WBC \\
\hline 07 & Adult & Male & $5 / 25 / 2001$ & 0.0 & 0.0 & 0.0 & 0.3 & 0.00 & 0.00 & 0.00 & 0.090 & NaI_WBC Note A \\
\hline 07 & Adult & Male & $9 / 18 / 2001$ & 1.9 & 2.0 & 1.7 & 0.9 & 0.00 & 0.00 & 0.00 & 0.075 & NaI_WBC Note A \\
\hline 12 & Adult & Male & $8 / 5 / 2001$ & 3.6 & 3.8 & 3.4 & 0.9 & 0.00 & 0.00 & 0.00 & 0.080 & NaI_WBC \\
\hline 13 & Adult & Male & $8 / 2 / 2001$ & 4.2 & 4.5 & 4.0 & 1.3 & 0.072 & 0.10 & 0.042 & 0.18 & NaI_WBC \\
\hline 26 & Adult & Male & $2 / 3 / 2001$ & 4.7 & 5.0 & 4.5 & 0.9 & 0.26 & 0.27 & 0.24 & 0.098 & NaI_WBC \\
\hline 26 & Adult & Male & $3 / 8 / 2001$ & 4.8 & 5.0 & 4.5 & 1.0 & 0.18 & 0.19 & 0.16 & 0.10 & NaI_WBC \\
\hline 26 & Adult & Male & $4 / 2 / 2001$ & 4.5 & 4.7 & 4.3 & 0.9 & 0.12 & 0.13 & 0.11 & 0.083 & NaI_WBC \\
\hline 26 & Adult & Male & $5 / 29 / 2001$ & 3.5 & 3.7 & 3.3 & 1.1 & 0.083 & 0.095 & 0.070 & 0.086 & NaI_WBC \\
\hline 26 & Adult & Male & $6 / 16 / 2001$ & 5.8 & 6.0 & 5.5 & 0.8 & 0.064 & 0.080 & 0.047 & 0.13 & NaI_WBC \\
\hline 26 & Adult & Male & $7 / 26 / 2001$ & 4.1 & 4.2 & 3.9 & 0.9 & 0.15 & 0.17 & 0.13 & 0.11 & NaI_WBC \\
\hline 26 & Adult & Male & $8 / 22 / 2001$ & 4.1 & 4.3 & 3.9 & 0.9 & 0.00 & 0.00 & 0.00 & 0.089 & NaI_WBC \\
\hline 26 & Adult & Male & $9 / 11 / 2001$ & 3.0 & 3.2 & 2.8 & 0.9 & 0.11 & 0.12 & 0.093 & 0.11 & NaI_WBC Note A \\
\hline 26 & Adult & Male & $10 / 21 / 2001$ & 0.0 & 0.0 & 0.0 & 0.7 & 0.15 & 0.17 & 0.14 & 0.12 & NaI_WBC Note A \\
\hline 29 & Adult & Male & $2 / 3 / 2001$ & 4.6 & 4.8 & 4.4 & 0.9 & 0.18 & 0.20 & 0.17 & 0.091 & NaI_WBC \\
\hline 29 & Adult & Male & $3 / 8 / 2001$ & 4.1 & 4.4 & 3.9 & 1.0 & 0.11 & 0.12 & 0.098 & 0.084 & NaI_WBC \\
\hline 29 & Adult & Male & $4 / 4 / 2001$ & 3.8 & 4.0 & 3.6 & 1.0 & 0.072 & 0.084 & 0.060 & 0.086 & NaI_WBC \\
\hline 29 & Adult & Male & $5 / 28 / 2001$ & 4.5 & 4.7 & 4.2 & 0.9 & 0.13 & 0.14 & 0.11 & 0.097 & NaI_WBC \\
\hline 29 & Adult & Male & $6 / 18 / 2001$ & 3.8 & 4.0 & 3.7 & 0.9 & 0.042 & 0.057 & 0.027 & 0.12 & NaI_WBC \\
\hline 29 & Adult & Male & $7 / 19 / 2001$ & 3.5 & 3.7 & 3.3 & 0.9 & 0.22 & 0.24 & 0.20 & 0.12 & NaI_WBC \\
\hline 29 & Adult & Male & $8 / 22 / 2001$ & 3.0 & 3.2 & 2.9 & 0.9 & 0.27 & 0.29 & 0.25 & 0.12 & NaI_WBC \\
\hline 29 & Adult & Male & $9 / 3 / 2001$ & 2.8 & 3.0 & 2.7 & 0.9 & 0.25 & 0.26 & 0.23 & 0.13 & NaI_WBC \\
\hline 29 & Adult & Male & $10 / 4 / 2001$ & 3.7 & 3.9 & 3.5 & 0.8 & 0.19 & 0.21 & 0.18 & 0.11 & NaI_WBC Note A \\
\hline 30 & Adult & Male & $3 / 11 / 2001$ & 4.5 & 4.7 & 4.2 & 0.9 & 0.12 & 0.13 & 0.10 & 0.089 & NaI_WBC \\
\hline 30 & Adult & Male & $5 / 20 / 2001$ & 0.0 & 0.0 & 0.0 & 0.7 & 0.038 & 0.051 & 0.025 & 0.092 & NaI_WBC Note A \\
\hline 30 & Adult & Male & $6 / 17 / 2001$ & 5.5 & 5.7 & 5.3 & 0.8 & 0.061 & 0.077 & 0.045 & 0.12 & NaI_WBC \\
\hline 30 & Adult & Male & $9 / 16 / 2001$ & 3.2 & 3.4 & 3.0 & 0.8 & 0.33 & 0.35 & 0.31 & 0.12 & NaI_WBC Note A \\
\hline 30 & Adult & Male & $10 / 21 / 2001$ & 2.9 & 3.1 & 2.8 & 0.9 & 0.30 & 0.32 & 0.28 & 0.12 & NaI_WBC Note A \\
\hline 32 & Adult & Male & $2 / 11 / 2001$ & 4.6 & 4.8 & 4.3 & 1.0 & 0.00 & 0.00 & 0.00 & 0.060 & NaI_WBC \\
\hline 32 & Adult & Male & $3 / 11 / 2001$ & 4.6 & 4.8 & 4.3 & 0.9 & 0.00 & 0.00 & 0.00 & 0.059 & NaI_WBC \\
\hline 32 & Adult & Male & $5 / 19 / 2001$ & 0.0 & 0.0 & 0.0 & 0.8 & 0.11 & 0.13 & 0.10 & 0.090 & NaI_WBC Note A \\
\hline 32 & Adult & Male & $7 / 20 / 2001$ & 3.8 & 4.0 & 3.7 & 0.9 & 0.00 & 0.00 & 0.00 & 0.081 & NaI_WBC \\
\hline 33 & Adult & Male & $2 / 6 / 2001$ & 3.7 & 3.9 & 3.5 & 1.0 & 0.52 & 0.55 & 0.50 & 0.10 & NaI_WBC \\
\hline 33 & Adult & Male & $3 / 11 / 2001$ & 4.7 & 4.9 & 4.4 & 0.9 & 0.36 & 0.39 & 0.34 & 0.10 & NaI_WBC \\
\hline 33 & Adult & Male & $5 / 21 / 2001$ & 1.3 & 1.6 & 1.0 & 0.3 & 0.47 & 0.50 & 0.44 & 0.15 & NaI_WBC Note A \\
\hline 33 & Adult & Male & $6 / 18 / 2001$ & 4.3 & 4.5 & 4.1 & 0.8 & 0.37 & 0.39 & 0.35 & 0.13 & NaI_WBC \\
\hline 38 & Adult & Male & $2 / 12 / 2001$ & 3.9 & 4.1 & 3.7 & 1.0 & 0.00 & 0.00 & 0.00 & 0.059 & NaI_WBC \\
\hline 38 & Adult & Male & $3 / 8 / 2001$ & 3.9 & 4.1 & 3.7 & 0.9 & 0.00 & 0.00 & 0.00 & 0.058 & NaI_WBC \\
\hline 38 & Adult & Male & $4 / 2 / 2001$ & 4.3 & 4.5 & 4.0 & 0.9 & 0.00 & 0.00 & 0.00 & 0.060 & NaI_WBC \\
\hline 38 & Adult & Male & $5 / 24 / 2001$ & 0.6 & 0.7 & 0.4 & 0.4 & 0.00 & 0.00 & 0.00 & 0.091 & NaI_WBC Note A \\
\hline 38 & Adult & Male & $6 / 22 / 2001$ & 3.4 & 3.6 & 3.2 & 0.9 & 0.00 & 0.00 & 0.00 & 0.077 & NaI_WBC \\
\hline 38 & Adult & Male & $8 / 19 / 2001$ & 3.5 & 3.7 & 3.3 & 0.9 & 0.00 & 0.00 & 0.00 & 0.077 & NaI_WBC \\
\hline 38 & Adult & Male & $9 / 14 / 2001$ & 3.3 & 3.4 & 3.1 & 0.8 & 0.00 & 0.00 & 0.00 & 0.076 & NaI_WBC Note A \\
\hline 54 & Adult & Male & $2 / 5 / 2001$ & 4.0 & 4.2 & 3.8 & 1.0 & 0.23 & 0.25 & 0.21 & 0.093 & NaI_WBC \\
\hline
\end{tabular}


Table 3. (Continued).

\begin{tabular}{|c|c|c|c|c|c|c|c|c|c|c|c|c|}
\hline \multirow[b]{2}{*}{ ID\# } & \multirow[b]{2}{*}{$\begin{array}{l}\text { Age } \\
\text { Type }\end{array}$} & \multirow[b]{2}{*}{ Gender } & \multirow[b]{2}{*}{$\begin{array}{l}\text { Count } \\
\text { Date }\end{array}$} & \multicolumn{4}{|c|}{${ }^{40} K(\mathrm{kBq})^{\mathrm{a}}$} & \multicolumn{4}{|c|}{${ }^{137} \mathrm{Cs}(\mathrm{kBq})^{\mathrm{a}}$} & \multirow[b]{2}{*}{ Code } \\
\hline & & & & Value & $\begin{array}{l}\text { Upper } \\
\text { Level }\end{array}$ & $\begin{array}{l}\text { Lower } \\
\text { Level }\end{array}$ & MDA & Value & $\begin{array}{l}\text { Upper } \\
\text { Level }\end{array}$ & $\begin{array}{c}\text { Lower } \\
\text { Level }\end{array}$ & MDA & \\
\hline 54 & Adult & Male & $3 / 11 / 2001$ & 4.6 & 4.8 & 4.4 & 0.9 & 0.12 & 0.13 & 0.11 & 0.085 & NaI_WBC \\
\hline 54 & Adult & Male & $4 / 1 / 2001$ & 4.6 & 4.9 & 4.4 & 0.9 & 0.11 & 0.13 & 0.10 & 0.083 & NaI_WBC \\
\hline 54 & Adult & Male & $5 / 21 / 2001$ & 1.0 & 1.2 & 0.8 & 0.4 & 0.13 & 0.15 & 0.11 & 0.13 & NaI_WBC Note A \\
\hline 54 & Adult & Male & $6 / 16 / 2001$ & 6.0 & 6.2 & 5.7 & 0.8 & 0.078 & 0.095 & 0.061 & 0.13 & NaI_WBC \\
\hline 54 & Adult & Male & $7 / 16 / 2001$ & 4.3 & 4.5 & 4.1 & 0.8 & 0.12 & 0.14 & 0.10 & 0.11 & NaI_WBC \\
\hline 54 & Adult & Male & $8 / 23 / 2001$ & 3.7 & 3.9 & 3.5 & 0.9 & 0.13 & 0.14 & 0.11 & 0.12 & NaI_WBC \\
\hline 54 & Adult & Male & $9 / 11 / 2001$ & 2.9 & 3.1 & 2.8 & 0.9 & 0.18 & 0.19 & 0.16 & 0.12 & NaI_WBC Note A \\
\hline 55 & Adult & Male & $8 / 5 / 2001$ & 4.0 & 4.2 & 3.8 & 0.9 & 0.00 & 0.00 & 0.00 & 0.080 & NaI_WBC \\
\hline 57 & Adult & Male & $4 / 6 / 2001$ & 4.8 & 5.0 & 4.6 & 0.9 & 0.00 & 0.00 & 0.00 & 0.062 & NaI_WBC \\
\hline 57 & Adult & Male & $5 / 29 / 2001$ & 3.4 & 3.6 & 3.2 & 1.1 & 0.00 & 0.00 & 0.00 & 0.062 & NaI_WBC \\
\hline 57 & Adult & Male & $6 / 17 / 2001$ & 6.2 & 6.4 & 5.9 & 0.8 & 0.00 & 0.00 & 0.00 & 0.080 & NaI_WBC \\
\hline 57 & Adult & Male & $8 / 25 / 2001$ & 3.9 & 4.0 & 3.7 & 0.9 & 0.11 & 0.13 & 0.092 & 0.12 & NaI_WBC \\
\hline 57 & Adult & Male & $9 / 4 / 2001$ & 4.7 & 4.9 & 4.5 & 0.8 & 0.00 & 0.00 & 0.00 & 0.085 & NaI_WBC \\
\hline 62 & Adult & Male & $2 / 11 / 2001$ & 4.8 & 5.0 & 4.6 & 1.0 & 0.16 & 0.18 & 0.15 & 0.085 & NaI_WBC \\
\hline 62 & Adult & Male & $3 / 11 / 2001$ & 5.3 & 5.5 & 5.0 & 0.9 & 0.068 & 0.081 & 0.055 & 0.089 & NaI_WBC \\
\hline 62 & Adult & Male & $4 / 2 / 2001$ & 6.1 & 6.3 & 5.8 & 0.9 & 0.00 & 0.00 & 0.00 & 0.064 & NaI_WBC \\
\hline 65 & Adult & Male & $2 / 6 / 2001$ & 3.9 & 4.1 & 3.7 & 1.0 & 0.19 & 0.21 & 0.18 & 0.083 & NaI_WBC \\
\hline 65 & Adult & Male & $3 / 8 / 2001$ & 4.4 & 4.6 & 4.2 & 0.9 & 0.17 & 0.19 & 0.16 & 0.091 & NaI_WBC \\
\hline 65 & Adult & Male & $4 / 2 / 2001$ & 4.7 & 4.9 & 4.5 & 0.9 & 0.11 & 0.12 & 0.097 & 0.088 & NaI_WBC \\
\hline 65 & Adult & Male & $5 / 19 / 2001$ & 0.0 & 0.0 & 0.0 & 0.8 & 0.15 & 0.17 & 0.14 & 0.092 & NaI_WBC Note A \\
\hline 65 & Adult & Male & $6 / 16 / 2001$ & 5.5 & 5.7 & 5.3 & 0.8 & 0.065 & 0.082 & 0.049 & 0.13 & NaI_WBC \\
\hline 65 & Adult & Male & $7 / 22 / 2001$ & 3.7 & 3.9 & 3.5 & 0.9 & 0.12 & 0.14 & 0.11 & 0.11 & NaI_WBC \\
\hline 65 & Adult & Male & $8 / 22 / 2001$ & 3.4 & 3.6 & 3.2 & 0.9 & 0.10 & 0.12 & 0.086 & 0.11 & NaI_WBC \\
\hline 65 & Adult & Male & $9 / 12 / 2001$ & 2.9 & 3.1 & 2.7 & 0.9 & 0.12 & 0.14 & 0.11 & 0.11 & NaI_WBC Note A \\
\hline 66 & Adult & Male & $2 / 12 / 2001$ & 3.0 & 3.2 & 2.8 & 1.0 & 0.00 & 0.00 & 0.00 & 0.059 & NaI_WBC \\
\hline 66 & Adult & Male & $3 / 11 / 2001$ & 4.0 & 4.2 & 3.8 & 0.9 & 0.00 & 0.00 & 0.00 & 0.059 & NaI_WBC \\
\hline 66 & Adult & Male & $5 / 20 / 2001$ & 1.6 & 1.7 & 1.4 & 1.0 & 0.00 & 0.00 & 0.00 & 0.061 & NaI_WBC Note A \\
\hline 66 & Adult & Male & $9 / 16 / 2001$ & 3.1 & 3.3 & 2.9 & 0.8 & 0.00 & 0.00 & 0.00 & 0.076 & NaI_WBC Note A \\
\hline 69 & Adult & Male & $2 / 6 / 2001$ & 4.1 & 4.3 & 3.9 & 1.0 & 0.16 & 0.17 & 0.15 & 0.089 & NaI_WBC \\
\hline 69 & Adult & Male & $3 / 10 / 2001$ & 4.4 & 4.6 & 4.2 & 0.9 & 0.12 & 0.13 & 0.10 & 0.091 & NaI_WBC \\
\hline 69 & Adult & Male & $5 / 21 / 2001$ & 0.9 & 1.1 & 0.7 & 0.4 & 0.13 & 0.15 & 0.11 & 0.14 & NaI_WBC Note A \\
\hline 69 & Adult & Male & $6 / 19 / 2001$ & 3.8 & 4.0 & 3.6 & 0.9 & 0.11 & 0.12 & 0.092 & 0.11 & NaI_WBC \\
\hline 69 & Adult & Male & $7 / 25 / 2001$ & 4.4 & 4.6 & 4.2 & 0.8 & 0.11 & 0.13 & 0.10 & 0.11 & NaI_WBC \\
\hline 69 & Adult & Male & $8 / 24 / 2001$ & 3.3 & 3.5 & 3.1 & 0.9 & 0.043 & 0.059 & 0.027 & 0.11 & NaI_WBC \\
\hline 69 & Adult & Male & $9 / 23 / 2001$ & 1.9 & 2.0 & 1.7 & 0.9 & 0.12 & 0.14 & 0.11 & 0.12 & NaI_WBC Note A \\
\hline 73 & Adult & Male & $2 / 6 / 2001$ & 3.3 & 3.5 & 3.1 & 1.0 & 0.081 & 0.093 & 0.069 & 0.085 & NaI_WBC \\
\hline 73 & Adult & Male & $3 / 9 / 2001$ & 4.6 & 4.8 & 4.4 & 0.9 & 0.044 & 0.055 & 0.032 & 0.085 & NaI_WBC \\
\hline 73 & Adult & Male & $5 / 18 / 2001$ & 0.0 & 0.0 & 0.0 & 0.7 & 0.00 & 0.00 & 0.00 & 0.064 & NaI_WBC Note A \\
\hline 73 & Adult & Male & $6 / 17 / 2001$ & 5.2 & 5.4 & 5.0 & 0.8 & 0.00 & 0.00 & 0.00 & 0.082 & NaI_WBC \\
\hline 73 & Adult & Male & $7 / 30 / 2001$ & 3.0 & 3.2 & 2.8 & 0.9 & 0.26 & 0.29 & 0.24 & 0.15 & NaI_WBC \\
\hline 73 & Adult & Male & $8 / 31 / 2001$ & 3.5 & 3.7 & 3.4 & 0.9 & 0.20 & 0.22 & 0.18 & 0.12 & NaI_WBC \\
\hline 73 & Adult & Male & $9 / 13 / 2001$ & 3.0 & 3.1 & 2.8 & 0.9 & 0.35 & 0.37 & 0.33 & 0.13 & NaI_WBC Note A \\
\hline 73 & Adult & Male & $10 / 21 / 2001$ & 3.1 & 3.3 & 3.0 & 0.9 & 0.20 & 0.21 & 0.18 & 0.11 & NaI_WBC Note A \\
\hline 76 & Adult & Male & $2 / 8 / 2001$ & 4.0 & 4.2 & 3.8 & 1.0 & 0.31 & 0.32 & 0.29 & 0.098 & NaI_WBC \\
\hline
\end{tabular}


Table 3. (Continued).

\begin{tabular}{|c|c|c|c|c|c|c|c|c|c|c|c|c|}
\hline \multirow[b]{2}{*}{ ID\# } & \multirow[b]{2}{*}{$\begin{array}{l}\text { Age } \\
\text { Type }\end{array}$} & \multirow[b]{2}{*}{ Gender } & \multirow[b]{2}{*}{$\begin{array}{l}\text { Count } \\
\text { Date }\end{array}$} & \multicolumn{4}{|c|}{${ }^{40} K(\mathbf{k B q})^{a}$} & \multicolumn{4}{|c|}{${ }^{137} \mathrm{Cs}(\mathrm{kBq})^{\mathrm{a}}$} & \multirow[b]{2}{*}{ Code } \\
\hline & & & & Value & $\begin{array}{l}\text { Upper } \\
\text { Level }\end{array}$ & $\begin{array}{l}\text { Lower } \\
\text { Level }\end{array}$ & MDA & Value & $\begin{array}{l}\text { Upper } \\
\text { Level }\end{array}$ & $\begin{array}{c}\text { Lower } \\
\text { Level }\end{array}$ & MDA & \\
\hline 76 & Adult & Male & $3 / 8 / 2001$ & 5.3 & 5.5 & 5.1 & 0.9 & 0.26 & 0.27 & 0.24 & 0.099 & NaI_WBC \\
\hline 76 & Adult & Male & $4 / 1 / 2001$ & 5.0 & 5.3 & 4.8 & 0.9 & 0.13 & 0.15 & 0.12 & 0.092 & NaI_WBC \\
\hline 76 & Adult & Male & $5 / 28 / 2001$ & 4.8 & 5.0 & 4.5 & 0.9 & 0.13 & 0.14 & 0.11 & 0.10 & NaI_WBC \\
\hline 76 & Adult & Male & $6 / 22 / 2001$ & 4.0 & 4.2 & 3.8 & 0.9 & 0.071 & 0.086 & 0.056 & 0.11 & NaI_WBC \\
\hline 76 & Adult & Male & $8 / 5 / 2001$ & 4.3 & 4.5 & 4.1 & 0.9 & 0.23 & 0.25 & 0.21 & 0.12 & NaI_WBC \\
\hline 76 & Adult & Male & $9 / 14 / 2001$ & 3.7 & 3.8 & 3.5 & 0.9 & 0.23 & 0.25 & 0.22 & 0.11 & NaI_WBC Note A \\
\hline 81 & Adult & Male & $5 / 23 / 2001$ & 0.9 & 1.1 & 0.7 & 0.3 & 0.00 & 0.00 & 0.00 & 0.092 & NaI_WBC Note A \\
\hline 86 & Adult & Male & $2 / 9 / 2001$ & 5.1 & 5.3 & 4.8 & 1.0 & 0.18 & 0.19 & 0.16 & 0.086 & NaI_WBC \\
\hline 98 & Adult & Male & $2 / 11 / 2001$ & 4.3 & 4.5 & 4.1 & 1.0 & 0.066 & 0.077 & 0.054 & 0.085 & NaI_WBC \\
\hline 98 & Adult & Male & $3 / 25 / 2001$ & 4.9 & 5.1 & 4.7 & 1.0 & 0.00 & 0.00 & 0.00 & 0.061 & NaI_WBC \\
\hline 98 & Adult & Male & $5 / 29 / 2001$ & 4.1 & 4.3 & 3.9 & 1.0 & 0.00 & 0.00 & 0.00 & 0.064 & NaI_WBC \\
\hline 98 & Adult & Male & $6 / 17 / 2001$ & 6.7 & 6.9 & 6.5 & 0.8 & 0.00 & 0.00 & 0.00 & 0.082 & NaI_WBC \\
\hline 98 & Adult & Male & $8 / 15 / 2001$ & 4.5 & 4.7 & 4.3 & 0.9 & 0.15 & 0.16 & 0.13 & 0.12 & NaI_WBC \\
\hline 98 & Adult & Male & $9 / 11 / 2001$ & 3.6 & 3.8 & 3.4 & 0.9 & 0.14 & 0.15 & 0.12 & 0.13 & NaI_WBC Note A \\
\hline 98 & Adult & Male & $10 / 11 / 2001$ & 2.9 & 3.1 & 2.7 & 0.9 & 0.11 & 0.12 & 0.094 & 0.11 & NaI_WBC Note A \\
\hline 111 & Adult & Male & $5 / 29 / 2001$ & 3.2 & 3.4 & 3.0 & 1.1 & 0.072 & 0.086 & 0.059 & 0.096 & NaI_WBC \\
\hline 111 & Adult & Male & $6 / 16 / 2001$ & 5.8 & 6.0 & 5.5 & 0.8 & 0.00 & 0.00 & 0.00 & 0.081 & NaI_WBC \\
\hline 111 & Adult & Male & $7 / 17 / 2001$ & 3.7 & 3.9 & 3.5 & 0.9 & 0.10 & 0.12 & 0.089 & 0.11 & NaI_WBC \\
\hline 111 & Adult & Male & $8 / 29 / 2001$ & 3.2 & 3.4 & 3.0 & 0.9 & 0.079 & 0.095 & 0.063 & 0.12 & NaI_WBC \\
\hline 111 & Adult & Male & $9 / 4 / 2001$ & 4.2 & 4.4 & 4.0 & 0.9 & 0.00 & 0.00 & 0.00 & 0.088 & NaI_WBC \\
\hline 120 & Adult & Male & $3 / 11 / 2001$ & 4.9 & 5.1 & 4.6 & 0.9 & 0.00 & 0.00 & 0.00 & 0.063 & NaI_WBC \\
\hline 120 & Adult & Male & $5 / 17 / 2001$ & 1.4 & 1.6 & 1.2 & 1.2 & 0.060 & 0.072 & 0.047 & 0.084 & NaI_WBC Note A \\
\hline 120 & Adult & Male & $7 / 1 / 2001$ & 3.7 & 3.9 & 3.6 & 0.8 & 0.19 & 0.21 & 0.17 & 0.13 & NaI_WBC \\
\hline 120 & Adult & Male & $7 / 29 / 2001$ & 3.5 & 3.7 & 3.3 & 0.9 & 0.12 & 0.14 & 0.089 & 0.15 & NaI_WBC \\
\hline 120 & Adult & Male & $8 / 23 / 2001$ & 3.9 & 4.1 & 3.7 & 0.9 & 0.066 & 0.082 & 0.050 & 0.11 & NaI_WBC \\
\hline 120 & Adult & Male & $9 / 13 / 2001$ & 3.3 & 3.5 & 3.1 & 0.9 & 0.14 & 0.16 & 0.13 & 0.12 & NaI_WBC Note A \\
\hline 120 & Adult & Male & $10 / 7 / 2001$ & 3.8 & 4.0 & 3.6 & 0.8 & 0.11 & 0.12 & 0.093 & 0.11 & NaI_WBC Note A \\
\hline 121 & Adult & Male & $2 / 5 / 2001$ & 4.1 & 4.3 & 3.8 & 1.0 & 0.14 & 0.16 & 0.13 & 0.095 & NaI_WBC \\
\hline 121 & Adult & Male & $3 / 10 / 2001$ & 4.3 & 4.6 & 4.1 & 1.0 & 0.046 & 0.059 & 0.034 & 0.090 & NaI_WBC \\
\hline 121 & Adult & Male & $4 / 6 / 2001$ & 4.9 & 5.2 & 4.7 & 0.9 & 0.00 & 0.00 & 0.00 & 0.062 & NaI_WBC \\
\hline 121 & Adult & Male & $5 / 21 / 2001$ & 0.8 & 1.0 & 0.7 & 0.4 & 0.45 & 0.48 & 0.42 & 0.16 & NaI_WBC Note A \\
\hline 121 & Adult & Male & $6 / 17 / 2001$ & 5.9 & 6.1 & 5.7 & 0.8 & 0.24 & 0.25 & 0.22 & 0.12 & NaI_WBC \\
\hline 121 & Adult & Male & $7 / 20 / 2001$ & 3.5 & 3.6 & 3.3 & 0.9 & 0.57 & 0.60 & 0.55 & 0.13 & NaI_WBC \\
\hline 121 & Adult & Male & $8 / 23 / 2001$ & 3.8 & 4.0 & 3.6 & 0.9 & 0.34 & 0.35 & 0.32 & 0.13 & NaI_WBC \\
\hline 121 & Adult & Male & $9 / 6 / 2001$ & 3.4 & 3.6 & 3.2 & 0.9 & 0.21 & 0.23 & 0.20 & 0.11 & NaI_WBC \\
\hline 121 & Adult & Male & $10 / 11 / 2001$ & 2.7 & 2.8 & 2.5 & 0.9 & 0.41 & 0.43 & 0.39 & 0.12 & NaI_WBC Note A \\
\hline 122 & Adult & Male & $2 / 6 / 2001$ & 4.9 & 5.1 & 4.6 & 1.0 & 0.038 & 0.050 & 0.027 & 0.083 & NaI_WBC \\
\hline 122 & Adult & Male & $3 / 11 / 2001$ & 5.4 & 5.7 & 5.2 & 1.0 & 0.00 & 0.00 & 0.00 & 0.062 & NaI_WBC \\
\hline 122 & Adult & Male & $5 / 17 / 2001$ & 1.7 & 1.8 & 1.5 & 1.1 & 0.14 & 0.15 & 0.13 & 0.097 & NaI_WBC Note A \\
\hline 122 & Adult & Male & $6 / 19 / 2001$ & 4.6 & 4.8 & 4.4 & 0.9 & 0.00 & 0.00 & 0.00 & 0.084 & NaI_WBC \\
\hline 122 & Adult & Male & $8 / 23 / 2001$ & 4.3 & 4.5 & 4.1 & 0.9 & 0.00 & 0.00 & 0.00 & 0.084 & NaI_WBC \\
\hline 122 & Adult & Male & $9 / 6 / 2001$ & 4.0 & 4.2 & 3.8 & 0.9 & 0.00 & 0.00 & 0.00 & 0.084 & NaI_WBC \\
\hline 123 & Adult & Male & $2 / 11 / 2001$ & 5.4 & 5.7 & 5.2 & 1.0 & 0.052 & 0.064 & 0.041 & 0.087 & NaI_WBC \\
\hline 123 & Adult & Male & $3 / 11 / 2001$ & 5.1 & 5.4 & 4.9 & 1.0 & 0.00 & 0.00 & 0.00 & 0.062 & NaI_WBC \\
\hline
\end{tabular}


Table 3. (Continued).

\begin{tabular}{|c|c|c|c|c|c|c|c|c|c|c|c|c|}
\hline \multirow[b]{2}{*}{ ID\# } & \multirow[b]{2}{*}{$\begin{array}{l}\text { Age } \\
\text { Type }\end{array}$} & \multirow[b]{2}{*}{ Gender } & \multirow[b]{2}{*}{$\begin{array}{l}\text { Count } \\
\text { Date }\end{array}$} & \multicolumn{4}{|c|}{${ }^{{ }^{40}} K(\mathrm{kBq})^{\mathrm{a}}$} & \multicolumn{4}{|c|}{${ }^{137} \mathrm{Cs}(\mathrm{kBq})^{\mathrm{a}}$} & \multirow[b]{2}{*}{ Code } \\
\hline & & & & Value & $\begin{array}{l}\text { Upper } \\
\text { Level }\end{array}$ & $\begin{array}{l}\text { Lower } \\
\text { Level }\end{array}$ & MDA & Value & $\begin{array}{l}\text { Upper } \\
\text { Level }\end{array}$ & $\begin{array}{c}\text { Lower } \\
\text { Level }\end{array}$ & MDA & \\
\hline 123 & Adult & Male & $5 / 20 / 2001$ & 2.0 & 2.2 & 1.8 & 1.1 & 0.00 & 0.00 & 0.00 & 0.065 & NaI_WBC Note A \\
\hline 123 & Adult & Male & $6 / 19 / 2001$ & 4.3 & 4.5 & 4.1 & 0.8 & 0.00 & 0.00 & 0.00 & 0.083 & NaI_WBC \\
\hline 123 & Adult & Male & $9 / 12 / 2001$ & 3.8 & 4.0 & 3.6 & 0.9 & 0.12 & 0.13 & 0.10 & 0.12 & NaI_WBC Note A \\
\hline 124 & Adult & Male & $2 / 11 / 2001$ & 4.2 & 4.4 & 3.9 & 1.0 & 0.038 & 0.049 & 0.028 & 0.087 & NaI_WBC \\
\hline 124 & Adult & Male & $3 / 11 / 2001$ & 4.8 & 5.0 & 4.6 & 0.9 & 0.00 & 0.00 & 0.00 & 0.062 & NaI_WBC \\
\hline 124 & Adult & Male & $5 / 17 / 2001$ & 1.9 & 2.1 & 1.7 & 1.1 & 0.039 & 0.051 & 0.028 & 0.085 & NaI_WBC Note A \\
\hline 124 & Adult & Male & $6 / 17 / 2001$ & 5.8 & 6.0 & 5.6 & 0.8 & 0.00 & 0.00 & 0.00 & 0.080 & NaI_WBC \\
\hline 124 & Adult & Male & $7 / 16 / 2001$ & 3.7 & 3.9 & 3.5 & 0.9 & 0.00 & 0.00 & 0.00 & 0.087 & NaI_WBC \\
\hline 124 & Adult & Male & $8 / 19 / 2001$ & 3.7 & 3.8 & 3.5 & 0.9 & 0.00 & 0.00 & 0.00 & 0.082 & NaI_WBC \\
\hline 124 & Adult & Male & $9 / 4 / 2001$ & 4.3 & 4.5 & 4.1 & 0.8 & 0.00 & 0.00 & 0.00 & 0.080 & NaI_WBC \\
\hline 124 & Adult & Male & $10 / 17 / 2001$ & 0.0 & 0.0 & 0.0 & 0.7 & 0.037 & 0.049 & 0.024 & 0.094 & NaI_WBC Note A \\
\hline 125 & Adult & Male & $2 / 11 / 2001$ & 4.0 & 4.2 & 3.8 & 1.0 & 0.00 & 0.00 & 0.00 & 0.060 & NaI_WBC \\
\hline 125 & Adult & Male & $3 / 11 / 2001$ & 4.8 & 5.0 & 4.6 & 1.0 & 0.00 & 0.00 & 0.00 & 0.059 & NaI_WBC \\
\hline 125 & Adult & Male & $4 / 1 / 2001$ & 4.6 & 4.8 & 4.4 & 0.9 & 0.00 & 0.00 & 0.00 & 0.059 & NaI_WBC \\
\hline 125 & Adult & Male & $5 / 17 / 2001$ & 1.7 & 1.8 & 1.5 & 1.2 & 0.00 & 0.00 & 0.00 & 0.062 & NaI_WBC Note A \\
\hline 125 & Adult & Male & $6 / 17 / 2001$ & 6.1 & 6.3 & 5.9 & 0.8 & 0.00 & 0.00 & 0.00 & 0.078 & NaI_WBC \\
\hline 125 & Adult & Male & $7 / 16 / 2001$ & 3.9 & 4.1 & 3.7 & 0.8 & 0.14 & 0.16 & 0.12 & 0.11 & NaI_WBC \\
\hline 125 & Adult & Male & $8 / 22 / 2001$ & 3.8 & 4.0 & 3.6 & 0.9 & 0.080 & 0.096 & 0.064 & 0.11 & NaI_WBC \\
\hline 126 & Adult & Male & $2 / 11 / 2001$ & 4.7 & 4.9 & 4.4 & 1.0 & 0.054 & 0.066 & 0.042 & 0.086 & NaI_WBC \\
\hline 126 & Adult & Male & $3 / 11 / 2001$ & 5.5 & 5.8 & 5.3 & 0.9 & 0.00 & 0.00 & 0.00 & 0.061 & NaI_WBC \\
\hline 126 & Adult & Male & $4 / 5 / 2001$ & 5.1 & 5.3 & 4.8 & 1.0 & 0.036 & 0.048 & 0.023 & 0.096 & NaI_WBC \\
\hline 126 & Adult & Male & $5 / 17 / 2001$ & 2.1 & 2.3 & 1.9 & 1.1 & 0.047 & 0.058 & 0.035 & 0.086 & NaI_WBC Note A \\
\hline 126 & Adult & Male & $6 / 22 / 2001$ & 4.4 & 4.6 & 4.2 & 0.9 & 0.00 & 0.00 & 0.00 & 0.081 & NaI_WBC \\
\hline 130 & Adult & Male & $2 / 11 / 2001$ & 4.0 & 4.2 & 3.8 & 1.0 & 0.033 & 0.045 & 0.021 & 0.088 & NaI_WBC \\
\hline 130 & Adult & Male & $5 / 19 / 2001$ & 2.9 & 3.1 & 2.7 & 1.1 & 0.00 & 0.00 & 0.00 & 0.066 & NaI_WBC \\
\hline 130 & Adult & Male & $7 / 22 / 2001$ & 3.9 & 4.1 & 3.7 & 0.9 & 0.039 & 0.054 & 0.024 & 0.11 & NaI_WBC \\
\hline 130 & Adult & Male & $9 / 3 / 2001$ & 3.0 & 3.2 & 2.8 & 1.0 & 0.00 & 0.00 & 0.00 & 0.085 & NaI_WBC \\
\hline 132 & Adult & Male & $2 / 12 / 2001$ & 5.2 & 5.4 & 4.9 & 1.0 & 0.078 & 0.091 & 0.066 & 0.084 & NaI_WBC \\
\hline 132 & Adult & Male & $3 / 10 / 2001$ & 5.6 & 5.9 & 5.4 & 1.0 & 0.099 & 0.11 & 0.086 & 0.096 & NaI_WBC \\
\hline 132 & Adult & Male & $5 / 29 / 2001$ & 3.9 & 4.1 & 3.7 & 1.1 & 0.087 & 0.10 & 0.074 & 0.091 & NaI_WBC \\
\hline 132 & Adult & Male & $6 / 20 / 2001$ & 5.3 & 5.5 & 5.1 & 0.8 & 0.00 & 0.00 & 0.00 & 0.085 & NaI_WBC \\
\hline 132 & Adult & Male & $8 / 24 / 2001$ & 4.6 & 4.8 & 4.4 & 0.9 & 0.080 & 0.096 & 0.064 & 0.11 & NaI_WBC \\
\hline 132 & Adult & Male & $10 / 17 / 2001$ & 2.6 & 2.8 & 2.5 & 0.9 & 0.058 & 0.072 & 0.044 & 0.11 & NaI_WBC Note A \\
\hline 136 & Adult & Male & $2 / 8 / 2001$ & 3.7 & 3.9 & 3.5 & 1.0 & 0.52 & 0.54 & 0.49 & 0.10 & NaI_WBC \\
\hline 136 & Adult & Male & $3 / 11 / 2001$ & 4.6 & 4.8 & 4.4 & 0.9 & 0.55 & 0.58 & 0.52 & 0.10 & NaI_WBC \\
\hline 136 & Adult & Male & $5 / 18 / 2001$ & 0.0 & 0.0 & 0.0 & 0.8 & 0.32 & 0.34 & 0.30 & 0.098 & NaI_WBC Note A \\
\hline 136 & Adult & Male & $7 / 19 / 2001$ & 3.9 & 4.1 & 3.7 & 0.9 & 0.50 & 0.52 & 0.47 & 0.13 & NaI_WBC \\
\hline 137 & Adult & Male & $2 / 5 / 2001$ & 4.7 & 5.0 & 4.5 & 1.0 & 0.22 & 0.23 & 0.20 & 0.099 & NaI_WBC \\
\hline 137 & Adult & Male & $3 / 8 / 2001$ & 5.3 & 5.6 & 5.1 & 0.9 & 0.18 & 0.20 & 0.16 & 0.098 & NaI_WBC \\
\hline 137 & Adult & Male & $4 / 6 / 2001$ & 5.2 & 5.5 & 5.0 & 0.9 & 0.056 & 0.069 & 0.044 & 0.085 & NaI_WBC \\
\hline 137 & Adult & Male & $5 / 29 / 2001$ & 3.4 & 3.6 & 3.2 & 1.0 & 0.15 & 0.17 & 0.14 & 0.096 & NaI_WBC \\
\hline 137 & Adult & Male & $6 / 20 / 2001$ & 4.7 & 4.9 & 4.5 & 0.8 & 0.074 & 0.090 & 0.059 & 0.11 & NaI_WBC \\
\hline 137 & Adult & Male & $8 / 3 / 2001$ & 4.1 & 4.3 & 4.0 & 0.9 & 0.38 & 0.41 & 0.36 & 0.15 & NaI_WBC \\
\hline 137 & Adult & Male & $9 / 3 / 2001$ & 3.6 & 3.8 & 3.4 & 1.0 & 0.34 & 0.36 & 0.32 & 0.13 & NaI_WBC \\
\hline
\end{tabular}


Table 3. (Continued).

\begin{tabular}{|c|c|c|c|c|c|c|c|c|c|c|c|c|}
\hline \multirow[b]{2}{*}{ ID\# } & \multirow[b]{2}{*}{$\begin{array}{l}\text { Age } \\
\text { Type }\end{array}$} & \multirow[b]{2}{*}{ Gender } & \multirow[b]{2}{*}{$\begin{array}{l}\text { Count } \\
\text { Date }\end{array}$} & \multicolumn{4}{|c|}{${ }^{40} \mathrm{~K}(\mathrm{kBq})^{\mathrm{a}}$} & \multicolumn{4}{|c|}{${ }^{137} \mathrm{Cs}(\mathrm{kBq})^{\mathrm{a}}$} & \multirow[b]{2}{*}{ Code } \\
\hline & & & & Value & $\begin{array}{l}\text { Upper } \\
\text { Level }\end{array}$ & $\begin{array}{l}\text { Lower } \\
\text { Level }\end{array}$ & MDA & Value & $\begin{array}{l}\text { Upper } \\
\text { Level }\end{array}$ & $\begin{array}{c}\text { Lower } \\
\text { Level }\end{array}$ & MDA & \\
\hline 137 & Adult & Male & $10 / 5 / 2001$ & 4.3 & 4.5 & 4.1 & 0.8 & 0.47 & 0.49 & 0.45 & 0.12 & NaI_WBC Note A \\
\hline 139 & Adult & Male & $2 / 10 / 2001$ & 4.1 & 4.3 & 3.9 & 1.0 & 0.00 & 0.00 & 0.00 & 0.060 & NaI_WBC \\
\hline 139 & Adult & Male & $3 / 11 / 2001$ & 4.5 & 4.7 & 4.3 & 1.0 & 0.00 & 0.00 & 0.00 & 0.059 & NaI_WBC \\
\hline 139 & Adult & Male & $5 / 24 / 2001$ & 0.8 & 0.9 & 0.6 & 0.4 & 0.00 & 0.00 & 0.00 & 0.095 & NaI_WBC Note A \\
\hline 139 & Adult & Male & $8 / 23 / 2001$ & 3.8 & 3.9 & 3.6 & 0.9 & 0.00 & 0.00 & 0.00 & 0.080 & NaI_WBC \\
\hline 139 & Adult & Male & $9 / 14 / 2001$ & 3.4 & 3.5 & 3.2 & 0.8 & 0.00 & 0.00 & 0.00 & 0.076 & NaI_WBC Note A \\
\hline 139 & Adult & Male & $10 / 11 / 2001$ & 3.1 & 3.3 & 3.0 & 0.9 & 0.00 & 0.00 & 0.00 & 0.074 & NaI_WBC Note A \\
\hline 140 & Adult & Male & 2/7/2001 & 3.6 & 3.8 & 3.4 & 1.0 & 0.00 & 0.00 & 0.00 & 0.058 & NaI_WBC \\
\hline 141 & Adult & Male & $2 / 10 / 2001$ & 5.2 & 5.4 & 4.9 & 1.0 & 0.00 & 0.00 & 0.00 & 0.059 & NaI_WBC \\
\hline 141 & Adult & Male & $3 / 11 / 2001$ & 5.0 & 5.2 & 4.7 & 1.0 & 0.00 & 0.00 & 0.00 & 0.059 & NaI_WBC \\
\hline 141 & Adult & Male & $5 / 18 / 2001$ & 0.4 & 0.6 & 0.3 & 1.2 & 0.13 & 0.14 & 0.11 & 0.077 & NaI_WBC Note A \\
\hline 141 & Adult & Male & $6 / 17 / 2001$ & 6.6 & 6.8 & 6.3 & 0.8 & 0.00 & 0.00 & 0.00 & 0.083 & NaI_WBC \\
\hline 141 & Adult & Male & $7 / 18 / 2001$ & 4.6 & 4.8 & 4.4 & 0.9 & 0.062 & 0.077 & 0.046 & 0.12 & NaI_WBC \\
\hline 141 & Adult & Male & $8 / 29 / 2001$ & 3.5 & 3.7 & 3.3 & 0.9 & 0.00 & 0.00 & 0.00 & 0.086 & NaI_WBC \\
\hline 141 & Adult & Male & $9 / 13 / 2001$ & 3.6 & 3.8 & 3.4 & 0.9 & 0.091 & 0.11 & 0.075 & 0.11 & NaI_WBC Note A \\
\hline 141 & Adult & Male & $10 / 6 / 2001$ & 4.3 & 4.5 & 4.1 & 0.8 & 0.082 & 0.097 & 0.068 & 0.10 & NaI_WBC Note A \\
\hline 142 & Adult & Male & $3 / 5 / 2001$ & 3.2 & 3.4 & 3.0 & 0.9 & 0.00 & 0.00 & 0.00 & 0.056 & NaI_WBC \\
\hline 143 & Adult & Male & $3 / 5 / 2001$ & 2.5 & 2.7 & 2.4 & 0.9 & 0.00 & 0.00 & 0.00 & 0.057 & NaI_WBC \\
\hline 143 & Adult & Male & $4 / 4 / 2001$ & 4.2 & 4.4 & 3.9 & 1.0 & 0.00 & 0.00 & 0.00 & 0.061 & NaI_WBC \\
\hline 143 & Adult & Male & $5 / 17 / 2001$ & 1.5 & 1.7 & 1.3 & 1.1 & 0.082 & 0.094 & 0.069 & 0.090 & NaI_WBC Note A \\
\hline 143 & Adult & Male & $6 / 27 / 2001$ & 3.8 & 4.0 & 3.6 & 0.8 & 0.14 & 0.16 & 0.13 & 0.11 & NaI_WBC \\
\hline 143 & Adult & Male & $7 / 31 / 2001$ & 3.7 & 3.9 & 3.5 & 0.9 & 0.17 & 0.20 & 0.14 & 0.15 & NaI_WBC \\
\hline 143 & Adult & Male & $8 / 22 / 2001$ & 3.5 & 3.7 & 3.3 & 0.9 & 0.072 & 0.088 & 0.056 & 0.11 & NaI_WBC \\
\hline 143 & Adult & Male & $9 / 4 / 2001$ & 4.8 & 5.0 & 4.6 & 0.8 & 0.00 & 0.00 & 0.00 & 0.087 & NaI_WBC \\
\hline 145 & Adult & Male & $3 / 25 / 2001$ & 4.7 & 4.9 & 4.5 & 0.9 & 0.00 & 0.00 & 0.00 & 0.061 & NaI_WBC \\
\hline 145 & Adult & Male & $5 / 18 / 2001$ & 1.1 & 1.2 & 0.9 & 1.1 & 0.054 & 0.066 & 0.042 & 0.084 & NaI_WBC Note A \\
\hline 145 & Adult & Male & $6 / 17 / 2001$ & 6.1 & 6.4 & 5.9 & 0.8 & 0.00 & 0.00 & 0.00 & 0.081 & NaI_WBC \\
\hline 145 & Adult & Male & $7 / 23 / 2001$ & 4.6 & 4.8 & 4.4 & 0.9 & 0.082 & 0.098 & 0.065 & 0.12 & NaI_WBC \\
\hline 145 & Adult & Male & $8 / 23 / 2001$ & 4.2 & 4.4 & 4.0 & 0.9 & 0.00 & 0.00 & 0.00 & 0.083 & NaI_WBC \\
\hline 146 & Adult & Male & $3 / 25 / 2001$ & 4.5 & 4.7 & 4.3 & 1.0 & 0.00 & 0.00 & 0.00 & 0.060 & NaI_WBC \\
\hline 146 & Adult & Male & $5 / 17 / 2001$ & 1.2 & 1.4 & 1.0 & 1.2 & 0.047 & 0.059 & 0.035 & 0.082 & NaI_WBC Note A \\
\hline 146 & Adult & Male & $6 / 20 / 2001$ & 4.0 & 4.2 & 3.8 & 0.9 & 0.00 & 0.00 & 0.00 & 0.080 & NaI_WBC \\
\hline 146 & Adult & Male & $7 / 18 / 2001$ & 4.1 & 4.3 & 3.9 & 0.9 & 0.00 & 0.00 & 0.00 & 0.081 & NaI_WBC \\
\hline 146 & Adult & Male & $8 / 19 / 2001$ & 4.2 & 4.4 & 4.0 & 0.9 & 0.095 & 0.11 & 0.079 & 0.12 & NaI_WBC \\
\hline 147 & Adult & Male & $3 / 25 / 2001$ & 4.4 & 4.6 & 4.2 & 1.0 & 0.00 & 0.00 & 0.00 & 0.059 & NaI_WBC \\
\hline 147 & Adult & Male & $5 / 19 / 2001$ & 0.0 & 0.0 & 0.0 & 0.8 & 0.062 & 0.075 & 0.050 & 0.086 & NaI_WBC Note A \\
\hline 148 & Adult & Male & $3 / 25 / 2001$ & 5.0 & 5.2 & 4.8 & 1.0 & 0.00 & 0.00 & 0.00 & 0.058 & NaI_WBC \\
\hline 148 & Adult & Male & $5 / 19 / 2001$ & 2.7 & 2.9 & 2.5 & 1.1 & 0.00 & 0.00 & 0.00 & 0.061 & NaI_WBC Note A \\
\hline 148 & Adult & Male & $6 / 19 / 2001$ & 4.5 & 4.7 & 4.3 & 0.9 & 0.00 & 0.00 & 0.00 & 0.078 & NaI_WBC \\
\hline 148 & Adult & Male & $7 / 22 / 2001$ & 5.0 & 5.2 & 4.8 & 0.8 & 0.073 & 0.089 & 0.056 & 0.11 & NaI_WBC \\
\hline 149 & Adult & Male & $3 / 25 / 2001$ & 4.7 & 4.9 & 4.4 & 0.9 & 0.031 & 0.043 & 0.020 & 0.083 & NaI_WBC \\
\hline 149 & Adult & Male & $6 / 20 / 2001$ & 4.2 & 4.4 & 4.0 & 0.8 & 0.12 & 0.14 & 0.10 & 0.13 & NaI_WBC \\
\hline 149 & Adult & Male & $7 / 29 / 2001$ & 4.1 & 4.3 & 4.0 & 0.9 & 0.27 & 0.30 & 0.24 & 0.16 & NaI_WBC \\
\hline 150 & Adult & Male & $3 / 25 / 2001$ & 4.4 & 4.6 & 4.2 & 0.9 & 0.00 & 0.00 & 0.00 & 0.059 & NaI_WBC \\
\hline
\end{tabular}


Table 3. (Continued).

\begin{tabular}{|c|c|c|c|c|c|c|c|c|c|c|c|c|c|}
\hline \multirow[b]{2}{*}{ ID\# } & \multirow[b]{2}{*}{$\begin{array}{l}\text { Age } \\
\text { Type }\end{array}$} & \multirow[b]{2}{*}{ Gender } & \multirow[b]{2}{*}{$\begin{array}{l}\text { Count } \\
\text { Date }\end{array}$} & \multicolumn{4}{|c|}{${ }^{40} K(\mathrm{kBq})^{\mathrm{a}}$} & \multicolumn{4}{|c|}{${ }^{137} \mathrm{Cs}(\mathrm{kBq})^{\mathrm{a}}$} & \multirow[b]{2}{*}{ Code } & \multirow[b]{2}{*}{ Notes } \\
\hline & & & & Value & $\begin{array}{l}\text { Upper } \\
\text { Level }\end{array}$ & $\begin{array}{l}\text { Lower } \\
\text { Level }\end{array}$ & MDA & Value & $\begin{array}{l}\text { Upper } \\
\text { Level }\end{array}$ & $\begin{array}{c}\text { Lower } \\
\text { Level }\end{array}$ & MDA & & \\
\hline 150 & Adult & Male & $5 / 22 / 2001$ & 1.0 & 1.2 & 0.7 & 0.4 & 0.12 & 0.14 & 0.10 & 0.14 & NaI_WBC & Note A \\
\hline 150 & Adult & Male & $6 / 22 / 2001$ & 3.3 & 3.5 & 3.2 & 0.8 & 0.00 & 0.00 & 0.00 & 0.081 & NaI_WBC & \\
\hline 151 & Adult & Male & $3 / 25 / 2001$ & 4.1 & 4.3 & 3.9 & 0.9 & 0.00 & 0.00 & 0.00 & 0.060 & NaI_WBC & \\
\hline 151 & Adult & Male & $5 / 24 / 2001$ & 0.6 & 0.7 & 0.4 & 0.4 & 0.00 & 0.00 & 0.00 & 0.092 & NaI_WBC & Note A \\
\hline 151 & Adult & Male & $8 / 19 / 2001$ & 3.6 & 3.8 & 3.4 & 0.9 & 0.00 & 0.00 & 0.00 & 0.078 & NaI_WBC & \\
\hline 153 & Adult & Male & 4/7/2001 & 5.1 & 5.4 & 4.9 & 0.9 & 0.00 & 0.00 & 0.00 & 0.060 & NaI_WBC & \\
\hline 153 & Adult & Male & $8 / 28 / 2001$ & 3.1 & 3.3 & 2.9 & 0.9 & 0.00 & 0.00 & 0.00 & 0.086 & NaI_WBC & \\
\hline 155 & Adult & Male & $9 / 18 / 2001$ & 0.0 & 0.0 & 0.0 & 0.7 & 0.090 & 0.11 & 0.074 & 0.12 & NaI_WBC & Note A \\
\hline 156 & Adult & Male & $5 / 20 / 2001$ & 1.9 & 2.0 & 1.7 & 1.1 & 0.00 & 0.00 & 0.00 & 0.065 & NaI_WBC & Note A \\
\hline 156 & Adult & Male & $7 / 1 / 2001$ & 3.7 & 3.8 & 3.5 & 0.8 & 0.00 & 0.00 & 0.00 & 0.077 & NaI_WBC & \\
\hline 156 & Adult & Male & $8 / 19 / 2001$ & 3.8 & 4.0 & 3.6 & 0.9 & 0.00 & 0.00 & 0.00 & 0.078 & NaI_WBC & \\
\hline 156 & Adult & Male & $9 / 11 / 2001$ & 2.5 & 2.7 & 2.4 & 0.9 & 0.00 & 0.00 & 0.00 & 0.073 & NaI_WBC & Note A \\
\hline 157 & Adult & Male & $5 / 25 / 2001$ & 1.0 & 1.2 & 0.8 & 0.4 & 0.15 & 0.17 & 0.13 & 0.14 & NaI_WBC & Note A \\
\hline 168 & Adult & Male & $7 / 1 / 2001$ & 4.1 & 4.3 & 3.9 & 0.9 & 0.00 & 0.00 & 0.00 & 0.078 & NaI_WBC & \\
\hline 170 & Adult & Male & $7 / 22 / 2001$ & 3.8 & 4.0 & 3.6 & 0.9 & 0.00 & 0.00 & 0.00 & 0.080 & NaI_WBC & \\
\hline 171 & Adult & Male & $7 / 29 / 2001$ & 4.0 & 4.1 & 3.8 & 0.9 & 0.00 & 0.00 & 0.00 & 0.078 & NaI_WBC & \\
\hline 172 & Adult & Male & $7 / 29 / 2001$ & 3.5 & 3.7 & 3.3 & 0.9 & 0.00 & 0.00 & 0.00 & 0.079 & NaI_WBC & \\
\hline 173 & Adult & Male & $8 / 5 / 2001$ & 4.5 & 4.7 & 4.3 & 0.9 & 0.00 & 0.00 & 0.00 & 0.080 & NaI_WBC & \\
\hline 174 & Adult & Male & $8 / 5 / 2001$ & 4.4 & 4.6 & 4.2 & 0.9 & 0.00 & 0.00 & 0.00 & 0.078 & NaI_WBC & \\
\hline 175 & Adult & Male & $8 / 19 / 2001$ & 3.5 & 3.7 & 3.3 & 0.9 & 0.00 & 0.00 & 0.00 & 0.079 & NaI_WBC & \\
\hline 176 & Adult & Male & $8 / 5 / 2001$ & 4.2 & 4.4 & 4.0 & 0.9 & 0.00 & 0.00 & 0.00 & 0.079 & NaI_WBC & \\
\hline 177 & Adult & Male & $8 / 19 / 2001$ & 4.6 & 4.8 & 4.4 & 0.9 & 0.087 & 0.10 & 0.072 & 0.12 & NaI_WBC & \\
\hline 178 & Adult & Male & $8 / 5 / 2001$ & 3.9 & 4.1 & 3.7 & 0.9 & 0.00 & 0.00 & 0.00 & 0.079 & NaI_WBC & \\
\hline 179 & Adult & Male & $8 / 5 / 2001$ & 4.0 & 4.2 & 3.8 & 0.9 & 0.00 & 0.00 & 0.00 & 0.078 & NaI_WBC & \\
\hline 180 & Adult & Male & $8 / 19 / 2001$ & 4.1 & 4.3 & 3.9 & 0.9 & 0.00 & 0.00 & 0.00 & 0.078 & NaI_WBC & \\
\hline 180 & Adult & Male & $9 / 14 / 2001$ & 3.9 & 4.1 & 3.8 & 0.9 & 0.17 & 0.19 & 0.16 & 0.11 & NaI_WBC & Note A \\
\hline 181 & Adult & Male & $8 / 5 / 2001$ & 4.8 & 5.0 & 4.6 & 0.9 & 0.00 & 0.00 & 0.00 & 0.082 & NaI_WBC & \\
\hline 182 & Adult & Male & $8 / 5 / 2001$ & 4.7 & 4.9 & 4.5 & 0.9 & 0.00 & 0.00 & 0.00 & 0.078 & NaI_WBC & \\
\hline 183 & Adult & Male & $8 / 5 / 2001$ & 4.3 & 4.5 & 4.1 & 0.9 & 0.00 & 0.00 & 0.00 & 0.079 & NaI_WBC & \\
\hline 184 & Adult & Male & $8 / 5 / 2001$ & 3.9 & 4.0 & 3.7 & 0.9 & 0.00 & 0.00 & 0.00 & 0.077 & NaI_WBC & \\
\hline 185 & Adult & Male & $8 / 5 / 2001$ & 4.1 & 4.3 & 4.0 & 0.9 & 0.00 & 0.00 & 0.00 & 0.081 & NaI_WBC & \\
\hline 186 & Adult & Male & $8 / 5 / 2001$ & 4.7 & 4.9 & 4.5 & 0.9 & 0.00 & 0.00 & 0.00 & 0.077 & NaI_WBC & \\
\hline 187 & Adult & Male & $8 / 5 / 2001$ & 4.4 & 4.6 & 4.2 & 0.9 & 0.00 & 0.00 & 0.00 & 0.081 & NaI_WBC & \\
\hline 188 & Adult & Male & $8 / 5 / 2001$ & 4.7 & 4.9 & 4.5 & 0.9 & 0.00 & 0.00 & 0.00 & 0.080 & NaI_WBC & \\
\hline 189 & Adult & Male & $8 / 5 / 2001$ & 4.4 & 4.6 & 4.2 & 0.9 & 0.00 & 0.00 & 0.00 & 0.084 & NaI_WBC & \\
\hline 190 & Adult & Male & $8 / 5 / 2001$ & 4.1 & 4.3 & 3.9 & 0.9 & 0.11 & 0.13 & 0.092 & 0.12 & NaI_WBC & \\
\hline 191 & Adult & Male & $8 / 5 / 2001$ & 5.2 & 5.4 & 5.0 & 0.9 & 0.00 & 0.00 & 0.00 & 0.077 & NaI_WBC & \\
\hline 193 & Adult & Male & $8 / 5 / 2001$ & 3.7 & 3.9 & 3.5 & 0.9 & 0.00 & 0.00 & 0.00 & 0.078 & NaI_WBC & \\
\hline 194 & Adult & Male & $8 / 5 / 2001$ & 4.5 & 4.7 & 4.3 & 0.9 & 0.00 & 0.00 & 0.00 & 0.078 & NaI_WBC & \\
\hline 195 & Adult & Male & $8 / 5 / 2001$ & 4.3 & 4.5 & 4.1 & 0.9 & 0.00 & 0.00 & 0.00 & 0.077 & NaI_WBC & \\
\hline 198 & Adult & Male & $9 / 19 / 2001$ & 3.4 & 3.6 & 3.2 & 0.9 & 0.00 & 0.00 & 0.00 & 0.077 & NaI_WBC & Note A. \\
\hline 199 & Adult & Male & $9 / 19 / 2001$ & 3.5 & 3.7 & 3.4 & 0.8 & 0.00 & 0.00 & 0.00 & 0.077 & NaI_WBC & Note A \\
\hline 200 & Adult & Male & $10 / 4 / 2001$ & 3.1 & 3.3 & 3.0 & 0.8 & 0.00 & 0.00 & 0.00 & 0.075 & NaI_WBC & Note A \\
\hline
\end{tabular}

a Upper and lower limits represent uncertainties in the measurements based on counting statistics $( \pm 1 \sigma)$. Note A: Suspect potassium-40 $\left({ }^{40} \mathrm{~K}\right)$ result, but Q.C. for cesium-137 $\left({ }^{137} \mathrm{Cs}\right)$ was within the acceptable range. 
Table 4. Rongelap plutonium urinalysis data (1998-99) from the University of Utah (Fission Track Analysis).

\begin{tabular}{|c|c|c|c|c|c|c|c|c|c|c|c|c|}
\hline \multirow[b]{3}{*}{ ID\# } & \multirow{3}{*}{$\begin{array}{l}\text { Age } \\
\text { Type }\end{array}$} & \multirow{3}{*}{ Gender } & \multirow{2}{*}{\multicolumn{2}{|c|}{ Collection }} & \multicolumn{3}{|c|}{${ }^{239} \mathrm{Pu}(\mu \mathrm{Bq})$} & \multicolumn{4}{|c|}{${ }^{240} \mathrm{Pu}(\mu \mathrm{Bq})^{\mathrm{a}}$} & \multirow[b]{3}{*}{ Notes } \\
\hline & & & & & Upper & Lower & & & Upper & Lower & & \\
\hline & & & Date & Value & Level & Level & MDA & Value & Level & Level & MDA & \\
\hline 01 & Adult & Male & 7/12/1998 & 7 & 12 & -29 & 0.22 & & & & & \\
\hline 02 & Adult & Male & 7/12/1998 & 2 & 12 & -12 & 0.22 & & & & & $\begin{array}{l}\text { Low analytical yield, } \\
\text { Split with LLNL. }\end{array}$ \\
\hline 03 & Adult & Male & 7/12/1998 & -2 & 1 & -12 & 0.22 & & & & & Split sample \\
\hline 03 & Adult & Male & 7/30/1999 & -9 & -2 & -57 & 0.22 & & & & & Split sample \\
\hline 03 & Adult & Male & 7/30/1999 & 19 & 29 & -79 & 0.22 & & & & & \\
\hline 04 & Adult & Male & 7/12/1998 & 48 & 73 & -194 & 0.22 & & & & & $\begin{array}{l}\text { Split sample \& split with } \\
\text { LLNL }\end{array}$ \\
\hline 04 & Adult & Male & 7/12/1998 & 32 & 54 & -132 & 0.22 & & & & & $\begin{array}{l}\text { Split sample \& split with } \\
\text { LLNL }\end{array}$ \\
\hline 05 & Adult & Male & 7/12/1998 & 1 & 4 & -5 & 0.22 & & & & & \\
\hline 05 & Adult & Male & 4/30/1999 & -1 & 0 & -3 & 0.22 & & & & & \\
\hline 06 & Adult & Male & 7/12/1998 & 19 & 30 & -79 & 0.22 & & & & & \\
\hline 07 & Adult & Male & 7/12/1998 & 11 & 17 & 5 & 0.22 & & & & & Low collection volume \\
\hline 08 & Adult & Male & 7/12/1998 & -3 & 17 & -68 & 0.22 & & & & & $\begin{array}{l}\text { Split sample \& split with } \\
\text { LLNL }\end{array}$ \\
\hline 08 & Adult & Male & 7/12/1998 & -8 & 0 & -47 & 0.22 & & & & & $\begin{array}{l}\text { Split sample \& split with } \\
\text { LLNL }\end{array}$ \\
\hline 08 & Adult & Male & 7/30/1999 & 21 & 33 & -86 & 0.22 & & & & & \\
\hline 09 & Adult & Male & 7/12/1998 & 6 & 9 & -24 & 0.22 & & & & & Split with LLNL \\
\hline 09 & Adult & Male & $5 / 2 / 1999$ & 12 & 18 & -49 & 0.22 & & & & & Split with LLNL \\
\hline 10 & Adult & Male & 7/12/1998 & 7 & 12 & -28 & 0.22 & & & & & $\begin{array}{l}\text { Low analytical yield, } \\
\text { split sample }\end{array}$ \\
\hline 10 & Adult & Male & 7/12/1998 & 19 & 38 & -79 & 0.22 & & & & & Split sample \\
\hline 11 & Adult & Male & 7/12/1998 & 10 & 16 & -41 & 0.22 & & & & & \\
\hline 12 & Adult & Male & 7/12/1998 & 35 & 53 & -142 & 0.22 & & & & & \\
\hline 13 & Adult & Male & 7/12/1998 & 2 & 5 & -7 & 0.22 & & & & & \\
\hline 14 & Adult & Male & 7/12/1998 & 18 & 29 & -74 & 0.22 & & & & & \\
\hline 14 & Adult & Male & 8/5/1999 & 0.2 & 4 & -5 & 0.22 & & & & & \\
\hline 15 & Adult & Male & 7/12/1998 & 30 & 54 & -123 & 0.22 & & & & & $\begin{array}{l}\text { Low analytical yield/low } \\
\text { collection volume }\end{array}$ \\
\hline 16 & Adult & Male & 7/12/1998 & 2 & 6 & -8 & 0.22 & & & & & Split with LLNL \\
\hline 16 & Adult & Male & 7/28/1999 & -1 & 3 & -8 & 0.22 & & & & & \\
\hline 17 & Adult & Male & 7/24/1998 & -3 & 2 & -19 & 0.22 & & & & & Split with LLNL \\
\hline 24 & Adult & Male & 4/30/1999 & 2 & 4 & -10 & 0.22 & & & & & \\
\hline 25 & Adult & Male & 4/30/1999 & 4 & 8 & -18 & 0.22 & & & & & Split sample \\
\hline 25 & Adult & Male & 4/30/1999 & -2 & 0 & -11 & 0.22 & & & & & Split sample \\
\hline 26 & Adult & Male & 4/30/1999 & 3 & 6 & -14 & 0.22 & & & & & \\
\hline 27 & Adult & Male & 4/30/1999 & 11 & 16 & -43 & 0.22 & & & & & \\
\hline 28 & Adult & Male & $5 / 1 / 1999$ & 14 & 47 & -56 & 0.22 & & & & & $\begin{array}{l}\text { Low analytical yield, } \\
\text { split with LLNL }\end{array}$ \\
\hline 29 & Adult & Male & $5 / 1 / 1999$ & 3 & 7 & -14 & 0.22 & & & & & Split sample \\
\hline 29 & Adult & Male & $5 / 1 / 1999$ & -4 & -2 & -25 & 0.22 & & & & & Split sample \\
\hline 30 & Adult & Male & $5 / 1 / 1999$ & & & & 0.22 & & & & & Sample lost \\
\hline 31 & Adult & Male & $5 / 1 / 1999$ & 29 & 43 & -119 & 0.22 & & & & & \\
\hline 32 & Adult & Male & $5 / 1 / 1999$ & 12 & 19 & -49 & 0.22 & & & & & \\
\hline 33 & Adult & Male & $5 / 2 / 1999$ & 29 & 45 & -117 & 0.22 & & & & & \\
\hline
\end{tabular}


Table 4. (Continued).

\begin{tabular}{|c|c|c|c|c|c|c|c|c|c|c|c|c|}
\hline \multirow[b]{3}{*}{ ID\# } & \multirow{3}{*}{$\begin{array}{l}\text { Age } \\
\text { Type }\end{array}$} & \multirow{2}{*}{\multicolumn{3}{|c|}{ Collection }} & \multicolumn{3}{|c|}{${ }^{239} \mathrm{Pu}(\mu \mathrm{Bq})$} & \multicolumn{4}{|c|}{${ }^{240} \mathrm{Pu}(\mu \mathrm{Bq})^{\mathrm{a}}$} & \multirow[b]{3}{*}{ Notes } \\
\hline & & & & & Upper & Lower & & & Upper & Lower & & \\
\hline & & Gender & Date & Value & Level & Level & MDA & Value & Level & Level & MDA & \\
\hline 34 & Adult & Male & $5 / 2 / 1999$ & 15 & 31 & -10 & 0.22 & & & & & \\
\hline 35 & Adult & Male & $5 / 3 / 1999$ & -3 & -1 & -21 & 0.22 & & & & & Split with LLNL \\
\hline 36 & Adult & Male & $5 / 3 / 1999$ & -4 & -2 & -27 & 0.22 & & & & & Split sample \\
\hline 36 & Adult & Male & $5 / 3 / 1999$ & 34 & 38 & 7 & 0.22 & & & & & Split sample \\
\hline 37 & Adult & Male & $5 / 3 / 1999$ & -1 & 1 & -22 & 0.22 & & & & & \\
\hline 38 & Adult & Male & $5 / 3 / 1999$ & 2 & 4 & -8 & 0.22 & & & & & Split sample \\
\hline 38 & Adult & Male & $5 / 3 / 1999$ & -6 & -3 & -37 & 0.22 & & & & & Split sample \\
\hline 43 & Adult & Male & $5 / 9 / 1999$ & 20 & 32 & -80 & 0.22 & & & & & \\
\hline 47 & Adult & Male & $7 / 29 / 1999$ & -2 & 1 & -12 & 0.22 & & & & & Split with LLNL \\
\hline 48 & Adult & Male & 8/5/1999 & 3 & 8 & -12 & 0.22 & & & & & Split sample \\
\hline 48 & Adult & Male & 8/5/1999 & 5 & 10 & -22 & 0.22 & & & & & Split sample \\
\hline 49 & Adult & Male & 8/5/1999 & 21 & 33 & -86 & 0.22 & & & & & \\
\hline
\end{tabular}

a Not possible to obtain ${ }^{240} \mathrm{Pu}$ by Fission Track Analysis 
Table 5. Plutonium urinalysis data for resettlement workers on Rongelap Island (CAMS/LLNL, 1998-2001)

\begin{tabular}{|c|c|c|c|c|c|c|c|c|c|c|c|c|}
\hline \multirow[b]{2}{*}{ ID\# } & & \multirow{2}{*}{\multicolumn{2}{|c|}{ Collection }} & \multicolumn{4}{|c|}{${ }^{239} \mathrm{Pu}(\mu \mathrm{Bq})$} & \multicolumn{4}{|c|}{${ }^{240} \mathrm{Pu}(\mu \mathrm{Bq})$} & \multirow[b]{2}{*}{ Notes } \\
\hline & $\begin{array}{l}\text { Age } \\
\text { Type }\end{array}$ & Gender & & Value & $\begin{array}{l}\text { Upper } \\
\text { Level }\end{array}$ & $\begin{array}{l}\text { Lower } \\
\text { Level }\end{array}$ & MDA & Value & $\begin{array}{l}\text { Upper } \\
\text { Level }\end{array}$ & $\begin{array}{l}\text { Lower } \\
\text { Level }\end{array}$ & MDA & \\
\hline 02 & Adult & Male & $7 / 12 / 1998$ & -0.7 & 1.2 & -2.5 & 4.5 & 0.0 & 1.2 & -1.2 & 14 & Split with Utah \\
\hline 04 & Adult & Male & $7 / 12 / 1998$ & 0.6 & 2.4 & -1.3 & 4.5 & 0.0 & 1.3 & -1.3 & 14 & Split with Utah \\
\hline 07 & Adult & Male & $6 / 6 / 2000$ & -0.4 & 0.3 & -1.1 & 1.9 & 0.0 & 2.6 & -2.6 & 8.2 & \\
\hline 08 & Adult & Male & $7 / 12 / 1998$ & 0.1 & 1.7 & -1.5 & 4.5 & 0.0 & 0.8 & -0.8 & 14 & Split with Utah \\
\hline 09 & Adult & Male & $7 / 12 / 1998$ & 3.1 & 7.1 & -1.0 & 4.5 & 0.0 & 2.4 & -2.4 & 14 & Split with Utah \\
\hline 09 & Adult & Male & $5 / 2 / 1999$ & 0.6 & 2.3 & -1.1 & 4.5 & 0.0 & 0.7 & -0.7 & 14 & Split with Utah \\
\hline 09 & Adult & Male & $5 / 30 / 2000$ & -0.4 & 0.3 & -1.0 & 1.9 & 0.0 & 2.0 & -2.1 & 8.2 & \\
\hline 16 & Adult & Male & $7 / 12 / 1998$ & -0.7 & 1.1 & -2.4 & 4.5 & 0.0 & 1.1 & -1.1 & 14 & Split with Utah \\
\hline 17 & Adult & Male & $7 / 24 / 1998$ & 0.7 & 2.5 & -1.0 & 4.5 & 0.0 & 0.8 & -0.8 & 14 & Split with Utah \\
\hline 28 & Adult & Male & $5 / 1 / 1999$ & 5.7 & 9.7 & 1.7 & 4.5 & 0.0 & 2.1 & -2.1 & 14 & Split with Utah \\
\hline 33 & Adult & Male & $1 / 17 / 2000$ & 2.0 & 4.2 & -0.1 & 6.5 & 2.5 & 3.6 & 1.4 & 5.5 & \\
\hline 33 & Adult & Male & $5 / 30 / 2000$ & 3.1 & 5.7 & 0.6 & 1.9 & 0.0 & 14 & -14.0 & 8.2 & \\
\hline 35 & Adult & Male & $5 / 3 / 1999$ & 0.8 & 2.6 & -1.0 & 4.5 & 2.6 & 3.7 & 1.5 & 14 & Split with Utah \\
\hline 35 & Adult & Male & $7 / 27 / 2001$ & 0.6 & 1.3 & -0.1 & 1.5 & 0.0 & 0.7 & -0.7 & 4.3 & \\
\hline 36 & Adult & Male & $6 / 6 / 2000$ & -0.4 & 1.3 & -2.0 & 1.9 & 0.0 & 11 & -11.4 & 8.2 & \\
\hline 37 & Adult & Male & $6 / 6 / 2000$ & & & & & & & & & Sample lost \\
\hline 43 (Control) & Adult & Male & 5/9/1999 & 0.6 & 2.5 & -1.3 & 4.5 & 0.0 & 1.3 & -1.3 & 14 & Split with Utah \\
\hline 45 (Control) & Adult & Male & $1 / 17 / 2000$ & 1.6 & 3.7 & -0.5 & 6.5 & 0.0 & 0.8 & -0.8 & 5.5 & \\
\hline 45 (Control) & Adult & Male & $5 / 30 / 2000$ & 2.1 & 3.2 & 0.9 & 1.9 & 0.0 & 3.0 & -3.1 & 8.2 & \\
\hline 50 & Adult & Male & 10/21/1999 & -2.7 & -1.1 & -4.4 & 3.7 & -6.4 & -4.3 & -8.6 & 50 & RALG worker \\
\hline 51 & Adult & Male & 10/21/1999 & -2.2 & -0.6 & -3.9 & 3.7 & -6.4 & -4.9 & -8.0 & 50 & RALG worker \\
\hline 52 & Adult & Male & 12/30/1999 & 0.4 & 2.1 & -1.4 & 3.7 & -6.4 & -4.3 & -8.6 & 50 & \\
\hline 53 & Adult & Male & 12/30/1999 & -0.9 & 0.8 & -2.6 & 3.7 & -6.4 & -4.6 & -8.3 & 50 & \\
\hline 54 & Adult & Male & 12/30/1999 & -0.7 & 1.0 & -2.4 & 3.7 & -6.4 & -4.4 & -8.5 & 50 & \\
\hline 55 & Adult & Male & $12 / 30 / 1999$ & 0.2 & 2.2 & -1.8 & 6.5 & 0.0 & 0.8 & -0.8 & 5.5 & \\
\hline 55 & Adult & Male & $6 / 6 / 2000$ & & & & & & & & & Sample lost \\
\hline 56 & Adult & Male & 12/30/1999 & 0.2 & 2.2 & -1.8 & 6.5 & 0.0 & 0.8 & -0.8 & 5.5 & \\
\hline 57 & Adult & Male & 12/30/1999 & -0.2 & 1.8 & -2.2 & 6.5 & 0.0 & 0.7 & -0.7 & 5.5 & \\
\hline 58 & Adult & Male & 12/30/1999 & 0.0 & 2.0 & -2.0 & 6.5 & 0.9 & 1.7 & 0.1 & 5.5 & \\
\hline 62 & Adult & Male & 12/30/1999 & 2.7 & 5.0 & 0.5 & 6.5 & 2.8 & 3.9 & 1.6 & 5.5 & \\
\hline 62 & Adult & Male & $5 / 30 / 2001$ & 0.4 & 1.1 & -0.4 & 1.9 & 0.0 & 2.2 & -2.2 & 8.2 & \\
\hline 66 & Adult & Male & 12/30/1999 & -0.2 & 1.8 & -2.2 & 6.5 & 0.0 & 0.8 & -0.8 & 5.5 & \\
\hline 74 & Adult & Male & $1 / 17 / 2000$ & 2.0 & 4.3 & -0.2 & 6.5 & 0.0 & 1.2 & -1.2 & 5.5 & \\
\hline 75 & Adult & Male & $1 / 17 / 2000$ & 1.8 & 4.0 & -0.3 & 6.5 & 0.0 & 1.0 & -1.0 & 5.5 & \\
\hline 86 & Adult & Male & $5 / 30 / 2000$ & 0.9 & 1.9 & -0.1 & 1.9 & 0.0 & 3.4 & -3.4 & 8.2 & \\
\hline 96 & Adult & Male & $6 / 6 / 2000$ & & & & & & & & & Sample lost \\
\hline 97 & Adult & Male & $6 / 6 / 2000$ & & & & & & & & & Sample lost \\
\hline 98 & Adult & Male & $6 / 6 / 2000$ & 0.2 & 1.0 & -0.5 & 1.9 & 0.0 & 2.7 & -2.7 & 8.2 & \\
\hline 128 & Adult & Male & $5 / 30 / 2001$ & 0.0 & 0.7 & -0.7 & 1.9 & 0.0 & 2.8 & -2.8 & 8.2 & \\
\hline 129 & Adult & Male & $5 / 30 / 2001$ & -0.4 & 0.7 & -1.4 & 1.9 & 0.0 & 6.7 & -6.8 & 8.2 & \\
\hline 131 & Adult & Male & $5 / 30 / 2001$ & 0.1 & 0.8 & -0.6 & 1.9 & 0.0 & 1.8 & -1.9 & 8.2 & \\
\hline 201 (Control) & Adult & Male & 3/7/2001 & 0.1 & 0.8 & -0.7 & 1.9 & 0.0 & 3.3 & -3.4 & 8.2 & \\
\hline Field Blank 1 & & & 7/19/1999 & 2.4 & 3.4 & 1.3 & 1.9 & 0.0 & 2.0 & -2.1 & 8.2 & \\
\hline Field Blank 2 & & & 7/19/1999 & 0.2 & 0.9 & -0.5 & 1.9 & 0.0 & 2.2 & -2.2 & 8.2 & \\
\hline Field Blank 3 & & & 7/19/1999 & 0.1 & 0.8 & -0.6 & 1.9 & 0.0 & 1.7 & -1.8 & 8.2 & \\
\hline
\end{tabular}


Table 5. (Continued).

\begin{tabular}{|c|c|c|c|c|c|c|c|c|c|c|c|c|}
\hline \multirow[b]{2}{*}{ ID\# } & \multirow[b]{2}{*}{$\begin{array}{l}\text { Age } \\
\text { Type }\end{array}$} & \multirow[b]{2}{*}{ Gender } & \multirow[b]{2}{*}{$\begin{array}{c}\text { Collection } \\
\text { Date }\end{array}$} & \multicolumn{4}{|c|}{${ }^{239} \mathrm{Pu}(\mu \mathrm{Bq})$} & \multicolumn{4}{|c|}{${ }^{240} \mathrm{Pu}(\mu \mathrm{Bq})$} & \multirow[b]{2}{*}{ Notes } \\
\hline & & & & Value & $\begin{array}{l}\text { Upper } \\
\text { Level }\end{array}$ & $\begin{array}{l}\text { Lower } \\
\text { Level }\end{array}$ & MDA & Value & $\begin{array}{c}\text { Upper } \\
\text { Level }\end{array}$ & $\begin{array}{l}\text { Lower } \\
\text { Level }\end{array}$ & MDA & \\
\hline Field Blank & & & $1 / 17 / 2000$ & 0.3 & 1.1 & -0.5 & 1.9 & 0.0 & 2.7 & -2.7 & 8.2 & \\
\hline Field Blank & & & $1 / 17 / 2000$ & 0.0 & 0.8 & -0.7 & 1.9 & 0.0 & 3.5 & -3.6 & 8.2 & \\
\hline Field Blanl & & & $5 / 30 / 2001$ & -0.2 & 0.4 & -0.8 & 1.9 & 0.0 & 1.4 & -1.5 & 8.2 & \\
\hline
\end{tabular}

a Verified urinalysis data as of December 31, 2001. 